\title{
Searching for the source of macroeconomic integration across advanced economies
}

\author{
Uluc Aysun* \\ University of Central Florida
}

January, 2015

\begin{abstract}
This paper estimates a two-country open economy DSGE model by using U.S. and Euro Area data. The baseline model, where the two regions are linked only through the trade of goods and risk-free bonds, fails to replicate the high cross-regional macroeconomic correlation in the data. I search for the determinants of this correlation by reconfiguring the model's shock processes in two ways. First, I include shocks that symmetrically affect each region. Second I allow for the transmission of shocks between the two regions. While both of these changes considerably improve the model's performance along the international dimension, common shocks appear to be the main drivers of cross-regional correlation. Under both specifications, comovements of variables are mostly determined by demand and financial shocks. Productivity, cost-push and exchange rate shocks, by contrast, play a limited role.

Keywords: Macroeconomic integration, DSGE, Bayesian estimation, U.S., Euro Area.

JEL Classification: E32; F41; F42; F44
\end{abstract}

*Department of Economics, University of Central Florida, College of Business Administration 4000 Central Florida Blvd., Orlando, Florida 32816-1991. Phone: +1 (530) 574-3951, fax: +1 (407) 823-3269, e-mail: uaysun@bus.ucf.edu. 


\section{Introduction}

Cross-country data from the past 3 decades indicate a high degree of macroeconomic integration amongst advanced economies. ${ }^{1}$ In this paper, I search for the source of this integration by building a two-country open economy, dynamic stochastic general equilibrium (DSGE) model and estimating it with U.S. and Euro Area data.

The initial inference is that the model, while providing a good representation of the domestic economies, falls noticeably short of replicating the high degree of international macroeconomic integration when the two regions are linked only through the trade of goods and risk-free bonds. This shortcoming is revealed through various post-estimation statistics/computations such as impulse responses, forecast error variance and historical decompositions and the disparity between data and model generated moments. Pointing out this anomaly, yet, is not the novel feature of my paper. Earlier studies such as Backus, Kehoe and Kydland (1992), Devereux, Gregory and Smith (1992) and Stockman and Tesar (1995), have already demonstrated the inadequacy of open economy models to replicate the high degree of output correlation across advanced economies. Prompted by these findings, ensuing research, some of which I discuss later in this section, have enriched these models in various ways and have included frictions that apply to cross-country linkages to more closely replicate international macroeconomic moments.

In this paper I take a different direction. Instead of enriching the model with various frictions and cross-regional linkages, I focus on the variation in the data that the model cannot explain to guide me in identifying the source of international macroeconomic integration. I do so by first reformulating the shock processes so that each shock is composed of a country specific component and a component that is common across the two regions. Estimation results corresponding to this specification indicate a much better fit to the data along the

\footnotetext{
${ }^{1}$ Figure 1 provides evidence for macroeconomic integration during the 1980Q1 to 2014Q2 period. The cross-country correlation coefficients that are computed by using the year-on-year growth rates of quarterly gross domestic product, consumer price indices (excluding energy and food items) and unemployment during this period are positive and high for most country pairs.
} 
international dimension. Compared to the baseline model, there is a considerable improvement in the model's ability to match cross-regional correlations and this improvement does not come at the expense of misrepresenting domestic moments. Consistent with this finding, common shocks constitute a large share in the historical decompositions of U.S. and Euro Area output, with shares approximately equaling the shares of domestic shocks, and forecast error variance decompositions at various horizons suggest that common shocks are important determinants of the variation in endogenous variables. Amongst the different types of common shocks, demand and financial shocks appear to be the main drivers of the macroeconomic correlation across the two regions (with investment and net worth shocks having the largest shares amongst demand and financial shocks, respectively) and productivity, cost-push and exchange rate shocks play a relatively small role.

I proceed by proposing an alternative mechanism that can explain the high degree of macroeconomic correlation in the data. This mechanism operates through the transmission of shocks from one region to the other and competes with the aforementioned common shock specification in accounting for macroeconomic integration. I incorporate and measure the strength of this mechanism by allowing each type of shock to be correlated across the two regions. Estimating the correlation coefficients and using them to compute various statistics, I then compare the model's performance to the model with common shock specification. The results indicate that each type of shock is positively correlated across the two regions and that there is a similar improvement in the model's ability to match cross-regional macroeconomic correlation. The marginal improvement over the model with common shocks, however, is small and forecast error variance decompositions indicate that common shocks generally explain a larger share of the variation of macroeconomic variables. The latter result becomes more apparent when I estimate a model that includes common shocks and allow for region-specific shocks to be correlated simultaneously. Compared to the model with only correlated shocks, the estimated correlation coefficients in this model are also smaller.

Besides their relative quantitative importance, there is another reason why common shocks 
may be a better way of accounting for international macroeconomic correlation compared to correlated shocks in a two large economy model. Specifically, when the shocks are correlated in the model, orthogonal shocks are identified by imposing a restriction on the contemporaneous correlation matrix. In my estimations this identification is achieved through a Cholesky restriction. Since each shock is of two types (a U.S. and a Euro Area shock), this restriction implies that the shock that is ordered first, U.S. shocks in my estimations, are not contemporaneously affected by Euro Area shocks. This is an unreasonable assumption given that the Euro Area economy is approximately as large as the U.S. economy. Furthermore, impulse responses corresponding to the baseline ordering indicate that while there is a strong transmission from the U.S. to the Euro Area, U.S. macroeconomic responses to Euro Area shocks are considerably small, especially compared to the responses to common shocks. The results are reversed when Euro Area shocks are ordered first.

The model in this paper features the financial accelerator mechanism of Bernanke, Gertler and Gilchrist (1999), includes various nominal and real rigidities, and allows me to investigate a large number of shocks and explore the real and financial linkages between the two regions. The baseline model includes 3 demand (government spending, consumption and investment shocks), 3 cost-push (wage, domestic and foreign price shocks), 3 financial (net worth, risk spread and risk-free interest rate shocks) and 1 productivity shock for each economy and a common exchange rate shock. To find the results discussed above, I solve the linearized form of the models by using a Bayesian estimation methodology. In doing so, I use 19 quarterly data series for the period 1998Q1 to 2013Q4 to estimate the parameters of the models. Although this methodology makes the analysis computationally intensive, especially given the size of the models (the baseline model has 116 variables and 71 parameters), it has a clear advantage over a calibration strategy for the research objective in this paper. Specifically, since the methodology allows me to estimate the size, persistence and the correlation of shocks, it is critical for identifying and quantifying the contribution of each shock to the cross-regional macroeconomic correlation. 
Overall, my results suggest that the symmetric movements of U.S. and Euro area macroeconomic variables could be caused by demand and financial shocks that are common to both regions. These findings complement the international business cycle literature that expanded after the low cross-country output correlation (and high consumption correlation) finding of Backus et al. (1992). Ensuing efforts to match the output correlation in the data by decreasing risk-sharing and consumption correlation in open economy models have been mostly devoted to two areas. While studies such as Obstfeld and Rogoff (2001), Backus, Kehoe, Kydland (1992), Zimmermann (1997), Ravn and Mazzenga (2004) use trade frictions to explain the lack of risk-sharing and the home-bias in portfolio holdings in the data, others such as Kollmann (1996), Kehoe and Perri (2002) and Heathcote and Perri (2002) account for the high output correlation in the data through incomplete asset markets. Following the 2008/09 crisis the latter channel has been reinforced by studies that incorporate global banks in open economy models (e.g. Alpanda and Aysun, 2014; Devereux and Yetman, 2010; Jeon, Olivero and Wu, 2013; Kollmann, Enders and Muller 2011). A separate strand of the literature explains the international alignment of business cycles by focusing on production processes that generate common productivity shocks and technology spillovers (e.g. Elliott and Fatás, 1996; Kose and Yi, 2001; Stockman and Tesar, 1995; Keller, 2004). Since common financial and demand (in particular investment) shocks are the main drivers of the comovements of variables in my model, and terms of trade, common price and common productivity shocks play a limited role, my results suggest that enriching open economy models with endogenous mechanisms that link the demand and financial sides of the two economies would a more effective and empirically relevant way of replicating the high degree of macroeconomic integration. Including financial frictions that apply symmetrically across both regions, for example, can generate symmetric responses in both regions through the easing/tightening of credit conditions in international capital markets and it can therefore decrease the explanatory power of the common shocks in my model.

My findings are also consistent with empirical evidence revealing the increasing impor- 
tance of common/global shocks and the cross-country transmission of shocks for international comovements of variables (e.g. Ambler et al., 2002; Canova and de Nicolo, 2003; Crucini et al., 2011; Kose et al., 2008; Schmitt-Grohe, 1998) in the post-Bretton Woods era. My findings based on a direct comparison of the contributions of commons shocks and shock transmission further indicate that common shocks are the more important drivers of the macroeconomic correlation between the U.S. and the Euro Area.

The rest of the paper is organized as follows. Section 2 outlines the model economy, Section 3 derives the optimality conditions from the model. Section 4 describes the estimation methodology. Section 5 discusses the baseline estimation results. Section 6 discusses the results obtained by including common and correlated shocks. Section 7 concludes.

\section{The model economies}

The framework is a two region open economy DSGE model where both regions are large and they are linked through the trade of goods and risk-free bonds. In this section I describe the agents in the economy and their optimization problems, and then I derive the corresponding first order conditions for only the domestic economy. I do this for brevity since the foreign economy is symmetrically modelled and it has the same agents who face similar constraints.

\section{$2.1 \quad$ Households}

The economy is populated by a continuum of households with infinite lives. In each period, the households, indexed by $j$, decide how much labor to supply and how much to save and consume by maximizing the following life-time utility function:

$$
U_{t}(j)=E_{0} \sum_{t=0}^{\infty} \tilde{\beta}^{t} \frac{\varepsilon_{c, t}}{1-\sigma}\left[\left(C_{t}(j)-\lambda C_{t-1}(j)\right) \exp \left(-\xi \frac{L_{t}(j)^{1+\sigma_{l}}}{1+\sigma_{l}}\right)\right]^{1-\sigma} N_{t}
$$


Here the variables $C_{t}(j)$ and $L_{t}(j)$ denote consumption and labor supply and $\sigma$ and $\sigma_{l}$ are the intertemporal elasticity of substitution and the inverse elasticity of labor supply, respectively. The utility of the consumers exhibits external habit persistence that is governed by the parameter $\lambda$, and $\xi$ is a level parameter that is calibrated to ensure that the steadystate value of labor is equal to $1 . \tilde{\beta}$ is the population growth rate adjusted time discount parameter. The variable $\varepsilon_{c, t}$ is a consumption shock that follows an $\mathrm{AR}(1)$ process given by $\varepsilon_{c, t}=\rho_{c} \varepsilon_{c, t-1}+\eta_{c, t}$ where $\rho_{c}$ is the persistence parameter, and $\eta_{c, t}$ is the shock innovation which is distributed i.i.d. normal with mean 0 and standard deviation $\sigma_{c}$. For the remaining shocks in the model, I use a similar parameterization with different subscripts and I assume that they similarly follow an $\mathrm{AR}(1)$ process. The mass of the households is represented by $N_{t}$ and it grows at the rate of $\eta$. In maximizing their utility function, the households face the following budget constraint:

$$
\begin{aligned}
& N_{t} C_{t}(j)+\frac{D_{t}(j)}{P_{t}}+\frac{B_{h, t}(j)}{R_{t} P_{t}}+E_{t} \frac{B_{f, t}(j)}{\varepsilon_{d, t} R_{t}^{*} P_{t}}+\frac{T_{t}}{P_{t}} \leq \frac{W_{t}(j)}{P_{t}} N_{t} L_{t}(j)+\frac{B_{h, t-1}(j)}{P_{t}} \\
+ & E_{t} \frac{B_{f, t-1}(j)}{\varepsilon_{d, t} P_{t}}+R_{t}^{d} \frac{D_{t-1}(j)}{P_{t}}+\Pi_{h, t}+\Pi_{f, t}+\frac{\kappa_{w}}{2}\left(\frac{W_{t}(j) / W_{t-1}(j)}{\gamma \pi_{t-1}^{\iota_{w}} \pi^{1-\iota_{w}}}-1\right)^{2} \frac{W_{t}}{P_{t}} N_{t} L_{t}
\end{aligned}
$$

where $P_{t}$ is the aggregate price level, $W_{t}$ and $W_{t}(j)$ are the aggregate wage rate and the wage rate received by household $\mathrm{j}$, respectively and $E_{t}$ is the exchange rate quoted as U.S. dollars per Euro. Besides their final goods consumption, the households hold one period nominally denominated domestic and foreign bonds, $B_{h, t}$ and $B_{f, t}$, that pay interest at the rate of $R_{t}$ and $R_{t}^{*}$ - also the central bank policy rates in the two economies -, make bank deposits, $D_{t}(j)$ , that pay interest at the rate of $R_{t}^{d}$, and pay lump-sum taxes, $T_{t}$, to the government. These expenditures are financed by their labor income, returns from previous period's bond holdings and deposits, and profits, $\Pi_{h, t}$ and $\Pi_{f, t}$, collected from domestic firms and importers (I describe these firms below). To include wage-stickiness in the model, I assume, similar to the formulation in Rotemberg (1982), that households incur quadratic wage adjustment costs given by the last term on the right hand side. In this expression, the level parameter $\kappa_{w}$ is 
given by $\kappa_{w}=\left(1-\xi_{w}\right)\left(1-\xi_{w} \tilde{\beta}\right) / 6 \xi_{w}$ with $\xi_{w}$ denoting the probability that wages are not adjusted in a given period, $\iota_{w}$ is the wage indexation parameter, $\gamma$ is the economy's steady state per-capita growth rate, and $\pi_{t}$ is the inflation rate given by $\pi_{t}=P_{t} / P_{t-1} \cdot{ }^{2}$ The variable is a domestic currency depreciation shock that can also be interpreted as a shock to the risk of holding domestic bonds.

The households have a monopoly over their labor supply, $L_{t}(j)$, and their services are hired by a perfectly competitive labor intermediary that transforms them into a composite labor service, $L_{t}$, according to the following Dixit and Stiglitz (1977) aggregator,

$$
L_{t}=\left[\int_{0}^{1} L_{t}(j)^{\frac{\Theta_{L, t}}{\Theta_{L, t}-1}} d j\right]^{\frac{\Theta_{L, t}-1}{\Theta_{L, t}}}
$$

and maximizes, $W_{t} L_{t}-\int_{0}^{1} W_{t}(j) L_{t}(j) d j$. This maximization problem generates the following labor demand curve:

$$
L_{t}(j)=\left[\frac{W_{t}(j)}{W_{t}}\right]^{-\Theta_{L, t}} L_{t}
$$

where $\Theta_{L, t}$ regulates the elasticity of substitution between the different labor services. To include cost push shocks that operate through wages, I assume that the time varying markup variable, $\varepsilon_{w, t}=\Theta_{L, t} /\left(\Theta_{L, t}-1\right)$, is governed by the following $\operatorname{AR}(1)$ process:

$$
\log \varepsilon_{w, t}=\left(1-\rho_{w}\right) \log \phi_{w}+\rho_{w} \log \varepsilon_{w, t-1}+\eta_{w, t}
$$

where $\phi_{w}$ is the gross mark-up of real wages over the marginal rate of substitution between consumption and leisure.

\footnotetext{
${ }^{2}$ The number 6 in the denominator of the expression for $\kappa_{w}$ is from the Kimball aggregator function in Smets and Wouters (2007).
} 


\subsection{Producers of intermediate, final and capital goods, and the importers}

Intermediate goods producers, indexed by $i$, are monopolistically competitive and they combine capital and labor to produce output according to the following Cobb-Douglas function:

$$
Y_{t}(i)=\varepsilon_{a, t}\left[Z_{t}(i) K_{t}(i)\right]^{\alpha}\left[A_{t} N_{t} L_{t}(i)\right]^{1-\alpha}-(\eta \gamma)^{t} f
$$

where $\varepsilon_{a, t}$ is an aggregate productivity shock, $Y_{t}(i), K_{t}(i), L_{t}(i)$ and $Z_{t}(i)$ are the firmspecific output, capital, labor and the capital utilization rate, $A_{t}$ is the trend level of productivity that grows at the rate of $\gamma$ and $f$ is the fixed cost of production that grows at the rate of $\eta \gamma$, the balanced growth rate of output. ${ }^{3}$

The capital hired by intermediate goods producers evolves according to the following function:

$$
K_{t}(i)=(1-\delta) K_{t-1}(i)+\left[1-\frac{\varphi}{2}\left(\frac{I_{t}(i)}{\eta \gamma I_{t-1}(i)}-1\right)^{2}\right] \varepsilon_{i, t} I_{t}(i)
$$

where $\varphi$ regulates investment adjustment costs, $I_{t}(i)$ denotes the amount of firm-specific investment and $\varepsilon_{i, t}$ is an investment-specific technology shock.

Capital is produced by perfectly competitive firms that convert undepreciated capital and final goods into new capital. In doing so, they purchase undepreciated capital from entrepreneurs - the capital owners in the model - at the price of $Q_{t}$ and final goods (investment) from final goods producers at the price of $P_{i, t}$, and they sell the new capital to entrepreneurs again at a price of $Q_{t}$. Their life-time profits are given by,

$$
E_{t} \sum_{t=0}^{\infty} \tilde{\beta}^{t} \Lambda_{t}\left[Q_{t} K_{t}-Q_{t}(1-\delta) K_{t-1}-\frac{P_{i, t}}{P_{t}} I_{t}\right]
$$

The stochastic discount factor, $\Lambda_{t}$, is identical to the Lagrange multiplier corresponding to

\footnotetext{
${ }^{3}$ The parameter $f$ is set equal to $(\theta-1) Y_{t} /(\eta \gamma)^{t}$. This condition ensures that the intermediate goods producers' profits are equal to zero along the balanced growth path
} 
the households' budget constraint and it is given by,

$$
\Lambda_{t}=\frac{\varepsilon_{c, t}}{N_{t}}\left(C_{t}-\lambda C_{t-1}\right)^{-\sigma} \exp \left(\frac{\sigma-1}{1+\sigma_{l}} \xi L_{t}^{1+\sigma_{l}}\right)
$$

Intermediate goods producers sell their products to perfectly-competitive final goods producers who combine the intermediate goods to form the final good, $Y_{t}$, as follows:

$$
Y_{t}=\left(\int_{0}^{1} Y_{t}(i)^{\left(\frac{\Theta_{h, t}-1}{\Theta_{h, t}}\right)} d i\right)^{\frac{\Theta_{h, t}}{\Theta_{h, t}-1}}
$$

The cost minimization problem of the final goods producers then yields the following firmspecific demand curve:

$$
Y_{t}(i)=\left(\frac{P_{t}(i)}{P_{t}}\right)^{-\Theta_{h, t}} Y_{t}
$$

Here $\Theta_{h, t}$ is the time-varying mark-up parameter which is subject to a cost-push shock according to the following process:

$$
\log \varepsilon_{h, t}=\left(1-\rho_{h}\right) \log \phi_{h}+\rho_{h} \log \varepsilon_{h, t-1}+\eta_{h, t}
$$

where $\varepsilon_{h, t}=\Theta_{h, t} /\left(\Theta_{h, t}-1\right)$ and $\phi_{h}$ is the steady state mark-up rate and $\eta_{h, t}$ is the cost push shock that follows an $\operatorname{AR}(1)$ process.

Given the demand function for their goods, the intermediate goods producers choose the price of their goods, $P_{h, t}(i)$, the amount of inputs and output that maximizes the following profit function:

$$
\begin{aligned}
\pi_{t}(i)=P_{h, t}(i) Y_{t}(i) & -W_{t} N_{t} L_{t}(i)-\left[M P K_{t}-\frac{\kappa_{z}}{1+\varpi}\left(z_{t}(i)^{1+\varpi}-1\right)\right] K_{t}(i) \\
& -\frac{\kappa_{p h}}{2}\left(\frac{P_{h, t}(i) / P_{h, t-1}(i)}{\pi_{h, t-1}^{\iota_{h}} \pi^{1-\iota_{h}}}-1\right)^{2} \frac{P_{h, t}}{P_{t}} Y_{t}
\end{aligned}
$$

where $M P K_{t}$ is the marginal product of capital (and also its rental rate). The formulation 
in equation (12) adds two frictions to the model. These frictions are added to enhance the model's ability to account for the empirical persistence in inflation through marginal cost and price stickiness. The first friction is generated by time-varying capacity utilization ratio, $z_{t}(i)$, and the costs incurred by adjusting this ratio and $\kappa_{z}$ and $\varpi$ capture the fixed costs and the elasticity of the cost of adjusting capacity utilization, respectively. The second friction is caused by the quadratic costs incurred by intermediate goods producers when the increase in their prices deviates from past inflation. Here, $\kappa_{p h}=\left(1-\xi_{h}\right)\left(1-\xi_{h} \tilde{\beta}\right) / 3.5 \xi_{h}$ is the fixed costs parameter with $\xi_{h}$ similarly denoting the probability that domestic goods prices are not adjusted during the current period and $\iota_{h}$ is the Calvo parameter that regulates the indexation to past inflation.

The importers in the economy are similar to the intermediate goods producers. They are monopolistically competitive, their products are combined to form a final good by perfectly competitive firms and they face costs of deviating from past inflation. Unlike intermediate goods producers, however, they do not produce. They purchase their goods from abroad, in foreign currency, differentiate their goods and sell them at a mark-up in the domestic market. The demand for imported goods, $Y_{f, t}(k)$ for importer $k$, is given by

$$
Y_{f, t}(k)=\left(\frac{P_{f, t}(k)}{P_{f, t}}\right)^{-\Theta_{f, t}} Y_{f, t}
$$

where $P_{f, t}(k)$ and $P_{f, t}$ are the firm-specific and the aggregate price of imports, $Y_{f, t}$ is the aggregate amount of imports, and the time-varying mark-up parameter, $\Theta_{f, t}$, is similarly subject to cost-push shocks according to:

$$
\log \varepsilon_{f, t}=\left(1-\rho_{f}\right) \log \phi_{f}+\rho_{f} \log \varepsilon_{f, t-1}+\eta_{f, t}
$$

where $\varepsilon_{f, t}=\Theta_{f, t} /\left(\Theta_{f, t}-1\right)$ and $\phi_{f}$ and $\eta_{f, t}$ represent the steady state mark-up rate and a cost push shock that follows an $\mathrm{AR}(1)$ process. 
The importers choose their prices and the amount of imports to maximize their life-time profits:

$$
E_{t} \sum_{t=0}^{\infty} \Lambda_{t}\left[\left(P_{f, t}(k)-E_{t} P_{h, t}^{*}\right) Y_{f, t}(k)-\frac{\kappa_{p f}}{2}\left(\frac{P_{f, t}(k) / P_{f, t-1}(k)}{\pi_{f, t}^{\iota_{f}} \pi_{f}^{1-\iota_{f}}}-1\right)^{2} P_{f, t} Y_{f, t}\right]
$$

where $\kappa_{p f}=\left(1-\xi_{f}\right)\left(1-\xi_{f} \tilde{\beta}\right) / 6 \xi_{f}$ with $\xi_{f}$ and $\iota_{f}$ similarly denoting the probability that import prices are not adjusted and the indexation parameter, respectively, and $\pi_{f, t}$ is the inflation rate for imported goods.

\subsection{Financial market}

The financial market in the economy operates through a single risk-neutral bank that lends, in nominal terms, to the entire population of entrepreneurs (mass of 1 ). The entrepreneurs are also risk neutral, and they collect the returns from capital and pay back their loans, $B_{t}$, with interest. Besides bank loans, the entrepreneurs finance their expenditures internally by using their net worth, $N_{t}$, so that $Q_{t} K_{t}=N_{t}+B_{t}$. In each period their returns to capital, $R_{k, t}(m)$ for entrepreneur $m$, is subject to an idiosyncratic shock, $w_{t}(m)$, so that $R_{k, t}(m)=w_{t}(m) R_{k, t}$, where $R_{k, t}$ is the aggregate returns to capital. $w_{t}$ is lognormally distributed with standard deviation $\sigma_{w, t}$ and mean $\mu_{w, t}=\sigma_{w, t}^{2}$ and its cumulative distribution is denoted by $F(w)$. Given this shock, the bank's participation condition for its contract with entrepreneur $m$ is given by,

$$
\begin{gathered}
{\left[1-F\left(\bar{w}_{t+1}(m)\right)\right] R_{e, t+1}(m) B_{t}(m)+(1-\mu) \int_{0}^{\bar{w}_{t+1}(m)} w_{t+1} d F(w) P_{t+1} R_{k, t+1} Q_{t} K_{t}(m)} \\
=R_{d, t} B_{t}(m)
\end{gathered}
$$


where $B_{t}(m)$ and $R_{e, t}(m)$ denote the amount of loans extended to entrepreneur $m$ and the interest rate on these loans, $\bar{w}_{t}(m)$ and is the cutoff value of the idiosyncratic shock below which entrepreneur $m$ defaults on her loan. If there is default the bank seizes the entrepreneur's assets and pays monitoring costs, $\mu$ per unit of assets. These costs are the source of financial friction in the model. The funds recovered by the bank in case of default are given by the second term on the right hand side of equation (16). The cutoff value of the technology shock is defined as,

$$
\bar{w}_{t}(m) P_{t+1} R_{k, t+1} Q_{t} K_{t}(m)=R_{e, t+1}(m) B_{t}(m)
$$

where the aggregate returns to capital is defined as,

$$
R_{k, t}=\frac{(1-\delta) Q_{t}+M P K_{t}}{Q_{t-1}}
$$

Notice here that the bank, by lending to the entire population of entrepreneurs, is able to diversify the idiosyncratic risk and receive the deposit rate of return. In doing so, it sets lending rates, $R_{e, t}$ above the deposit rate to compensate for the costs incurred when monitoring bad loans.

Given the financial contract the entrepreneur $m$ 's net worth, $N_{t}(m)$ evolves according to:

$$
\begin{gathered}
N_{t}(m)=\gamma_{e, t}\left[1-F\left(\bar{w}_{t}(m)\right)\right]\left[R_{k, t}(m) Q_{t-1} K_{t-1}(m)-R_{e, t}(m)\left(Q_{t-1} K_{t-1}(m)-N_{t-1}(m)\right)\right] \\
+\left(1-\gamma_{e, t}\right)
\end{gathered}
$$

where $\gamma_{e, t}$ is the survival rate of entrepreneurs that is set to a number less than one to ensure that the entrepreneurs do not accumulate enough net worth to become self-financing. If the entrepreneur dies, it is replaced by a new entrepreneur who begins with a unit of net worth that is obtained from households. 
In the financial market there are two types of shocks. The first shock, denoted by $\varepsilon_{k, t}$, is transmitted to the economy through returns to capital and it is modelled as a shock (following an $\operatorname{AR}(1)$ process) to the standard deviation of $w_{t}$ as follows:

$$
\log \sigma_{w, t}=\left(1-\rho_{k}\right) \sigma_{w}+\rho_{k} \log \sigma_{w, t-1}+\varepsilon_{k, t}
$$

The second shock, denoted by $\varepsilon_{n, t}$, is transmitted through entrepreneurs' net worth by impacting their survival rate. The process governing this impact is similar to that in equation $(21)$.

\subsection{Monetary policy and fiscal balance}

The monetary policy in the economy is formulated according to the following Taylor-rule:

$$
R_{t}=\rho R_{t-1}+(1-\rho)\left(\log R+\gamma_{\pi} \log \frac{\pi_{t}}{\pi}+\gamma_{y} \log \frac{Y_{t}}{(\gamma \eta)^{t} Y}+\gamma_{\Delta y} \log \frac{Y_{t}}{\gamma \eta Y_{t-1}}\right)+\varepsilon_{r, t}
$$

where $\gamma_{\pi}, \gamma_{y}$ and $\gamma_{y}$ are the relative weights of inflation, output gap and output growth, $R$ is the steady state level of the nominal policy rate, $\rho$ is the interest rate smoothing parameter, and the policy shock variable, $\varepsilon_{r, t}$, similarly follows an $\operatorname{AR}(1)$ process.

The government finances its real expenditures, $G_{t}$, and debt payments by collecting lumpsum taxes from households and issuing new discount bonds:

$$
P_{t} G_{t}+B_{h, t-1}+B_{f, t-1}^{*}=T_{t}+\frac{B_{h, t}}{R_{t}}+\frac{B_{f, t}^{*}}{R_{t}}
$$

where $B_{f, t}^{*}$ is the amount of domestic government bonds held by foreign households. 


\subsection{Composite goods and market clearing conditions}

Consumption and investment goods are the following CES aggregates of domestic and foreign goods, $C_{h, t}$ and $C_{f, t}$ for consumption goods and $I_{h, t}$ and $I_{f, t}$ for investment goods,

$$
\begin{gathered}
C_{t}=\left(\gamma_{c}^{1 / \lambda_{c}} C_{h, t}^{\left(\lambda_{c}-1\right) / \lambda_{c}}+\left(1-\gamma_{c}\right)^{1 / \lambda_{c}} C_{f, t}^{\left(\lambda_{c}-1\right) / \lambda_{c}}\right)^{\lambda_{c} /\left(\lambda_{c}-1\right)} \\
I_{t}=\left(\gamma_{i}^{1 / \lambda_{i}} I_{h, t}^{\left(\lambda_{i}-1\right) / \lambda_{i}}+\left(1-\gamma_{i}\right)^{1 / \lambda_{i}} I_{f, t}^{\left(\lambda_{i}-1\right) / \lambda_{i}}\right)^{\lambda_{i} /\left(\lambda_{i}-1\right)}
\end{gathered}
$$

where $\gamma_{c}$ and $\gamma_{i}$ are the share of domestic goods in aggregate consumption and investment, respectively, and $\lambda_{c}$ and $\lambda_{i}$ determine the elasticity of substitution between home and foreign goods in the consumption and investment aggregators, respectively. The demand functions for home and foreign goods and the aggregate price indices that correspond to equations (24) and (25) are given by,

$$
\begin{gathered}
C_{h, t}=\left(\frac{P_{h, t}}{P_{t}}\right)^{-\lambda_{c}} \gamma_{c} C_{t} \quad \text { and } \quad C_{f, t}=\left(\frac{P_{f, t}}{P_{t}}\right)^{-\lambda_{c}}\left(1-\gamma_{c}\right) C_{t} \\
I_{h, t}=\left(\frac{P_{h, t}}{P_{i, t}}\right)^{-\lambda_{i}} \gamma_{i} I_{t} \quad \text { and } \quad I_{f, t}=\left(\frac{P_{f, t}}{P_{i, t}}\right)^{-\lambda_{i}}\left(1-\gamma_{i}\right) I_{t} \\
P_{t}=\left(\gamma_{c} P_{h, t}^{1-\lambda_{c}}+\left(1-\gamma_{c}\right) P_{f, t}^{1-\lambda_{c}}\right)^{1 /\left(1-\lambda_{c}\right)} \\
P_{i, t}=\left(\gamma_{i} P_{h, t}^{1-\lambda_{i}}+\left(1-\gamma_{i}\right) P_{f, t}^{1-\lambda_{i}}\right)^{1 /\left(1-\lambda_{i}\right)}
\end{gathered}
$$

The production of each economy equals the sum of home goods consumption and investment expenditures, government expenditures and the foreign economy's imports of consumption and investment goods,

$$
Y_{t}=N_{t} C_{h, t}+I_{h, t}+G_{t}+N_{t}^{*} C_{f, t}^{*}+I_{f, t}^{*}
$$


where the foreign imports, $Y_{f, t}$, are only used for consumption and investment,

$$
Y_{f, t}=N_{t} C_{f, t}+I_{f, t}
$$

Bank loans in each economy are financed by the deposits of local households,

$$
B_{t}=D_{t}
$$

\section{Optimality conditions}

The maximization of the households' utility function with respect to deposit holdings yields the following conventional Euler condition:

$$
E_{t}\left[\tilde{\beta} \frac{\Lambda_{t+1}}{\Lambda_{t}} \frac{R_{t}^{d}}{\pi_{t+1}}\right]=1
$$

where the Lagrange multiplier $\Lambda_{t}$ measures the marginal utility and the marginal budget costs of consumption. There is arbitrage between deposit rates and domestic bond holdings so that, $R_{t}=R_{t}^{d}$, and the arbitrage between the domestic and foreign bond is represented by the following uncovered interest parity condition:

$$
E_{t}\left[\tilde{\beta} \frac{\Lambda_{t+1}}{\Lambda_{t} \pi_{t+1}}\left(R_{t}-\varepsilon_{d, t} \frac{E_{t+1}}{E_{t}} R_{t}^{*}\right)\right]=0
$$

Labor supply decisions and wage setting behavior are governed by the following optimality conditions:

$$
\varepsilon_{c, t}\left[\left(C_{t}-\lambda C_{t-1}\right) \exp \left(-\xi \frac{L_{t}^{1+\sigma_{l}}}{1+\sigma_{l}}\right)\right]^{1-\sigma} \xi L_{t}^{\sigma_{l}}=\Lambda_{t} \Omega_{t} \frac{W_{t}}{P_{t}}
$$




$$
\begin{gathered}
\left(\frac{\pi_{w, t}}{\gamma \pi_{t-1}^{\iota_{w}} \pi^{1-\iota_{w}}}-1\right) \frac{\pi_{w, t}}{\gamma \pi_{t-1}^{\iota_{w}} \pi^{1-\iota_{w}}}= \\
E_{t}\left[\left(\tilde{\beta} \frac{\Lambda_{t+1}}{\Lambda_{t}}\right)\left(\frac{\pi_{w, t+1}}{\gamma \pi_{t}^{\iota_{w}} \pi^{1-\iota_{w}}}-1\right) \frac{\pi_{w, t+1}^{2}}{\gamma \pi_{t}^{\iota_{w}} \pi^{1-\iota_{w}} \pi_{t+1}} \frac{N_{t+1} L_{t+1}}{N_{t} L_{t}}\right]+\Omega_{t} \frac{\left(\Theta_{L, t}-1\right)}{\kappa_{w}} \varepsilon_{w, t}
\end{gathered}
$$

where $\Omega_{t}=W_{t}(i)\left(\frac{L_{t}(i)}{L_{t}}\right)^{1 / \Theta_{L, t}}$ is the Lagrange multiplier corresponding to the labor intermediaries budget constraint.

The optimization problem of the bank, as in Bernanke et al. (1999) and FernandezVillaverde (2010), produces a relationship between entrepreneurs' leverage and their borrowing premium:

$$
\frac{Q_{t} K_{t}}{N_{t}}=v_{E}\left(\frac{E_{t} \pi_{t+1} R_{k, t+1}}{R_{d, t}}\right)
$$

where an increase leverage causes the wedge between the borrowing rate and the deposit rate to grow.

The intermediate goods producers maximize profits subject to the final goods producers' demand for their goods. Profit maximization with respect to labor, capital and the utilization rate generates the following conditions:

$$
\begin{gathered}
\Omega_{h, t} P_{h, t}(1-\alpha)\left(Y_{t}+(\eta \gamma)^{t} f\right)=W_{t} L_{t} \\
\Omega_{h, t} \frac{P_{h, t}}{P_{t}} \alpha\left(\frac{Y_{t}+(\eta \gamma)^{t} f}{K_{t}}\right)=M P K_{t}+\frac{\kappa_{z}}{1+\varpi}\left(Z_{t}^{1+\varpi}-1\right) \\
\Omega_{h, t} \frac{P_{h, t}}{P_{t}} \alpha\left(\frac{Y_{t}+(\eta \gamma)^{t} f}{Z_{t}}\right)=\kappa_{z} Z_{t}^{\varpi} K_{t}
\end{gathered}
$$

where $\Omega_{h, t}$ is the Lagrange multiplier corresponding to the final goods producers budget constraint.

Price setting behavior of the intermediate goods producers and the imports are given by 
the following equations that demonstrate rigidity similar to equation (36):

$$
\begin{gathered}
\left(\frac{\pi_{h, t}}{\pi_{t-1}^{\iota_{h}} \pi^{1-\iota_{h}}}-1\right) \frac{\pi_{h, t}}{\pi_{t-1}^{\iota_{h}} \pi^{1-\iota_{h}}}=E_{t}\left[\left(\frac{\tilde{\beta} \Lambda_{t+1}}{\Lambda_{t}}\right)\left(\frac{\pi_{h, t+1}}{\pi_{t}^{\iota_{h}} \pi^{1-\iota_{h}}}-1\right) \frac{\pi_{h, t+1} Y_{t+1}}{\pi_{t}^{\iota_{h}} \pi^{1-\iota_{h}} Y_{t}}\right]+\frac{\Omega_{h, t}\left(\Theta_{h, t}-1\right) \varepsilon_{h, t}}{\kappa_{p h}} \\
\left(\frac{\pi_{f, t}}{\pi_{f, t-1}^{\iota_{f}} \pi^{1-\iota_{f}}}-1\right) \frac{\pi_{f, t}}{\pi_{f, t-1}^{\iota_{f}} \pi^{1-\iota_{f}}}= \\
E_{t}\left[\left(\tilde{\beta} \frac{\Lambda_{t+1}}{\Lambda_{t}}\right)\left(\frac{\pi_{f, t+1}}{\pi_{f, t}^{\iota_{f}} \pi^{1-\iota_{f}}}-1\right) \frac{\pi_{f, t+1}}{\pi_{f, t}^{\iota_{f}} \pi^{1-\iota_{f}}} \frac{\pi_{f, t+1}}{\pi_{t+1}} \frac{Y_{f, t+1}}{Y_{f, t}}\right]+\frac{\left(1-\Theta_{f, t}\right)}{\kappa_{p f}}\left(1-\frac{e_{t} P_{h, t}^{*}}{P_{f, t}} \varepsilon_{f, t}\right)
\end{gathered}
$$

where $\pi_{f, t}=P_{f, t} / P_{f, t-1}$ denotes import price inflation.

Capital producers' maximization of their life-time profits with respect to investment goods produces the following condition:

$$
\begin{aligned}
\frac{P_{i, t}}{P_{t}} & =q_{t} \varepsilon_{i, t}\left(1-\varphi\left(\frac{I_{t}}{\eta \gamma I_{t-1}}-1\right) \frac{I_{t}}{\eta \gamma I_{t-1}}-\frac{\varphi}{2}\left(\frac{I_{t}}{\eta \gamma I_{t-1}}-1\right)^{2}\right) \\
& +E_{t}\left[\beta \varphi \frac{\Lambda_{t+1}}{\Lambda_{t}} q_{t+1} \varepsilon_{i, t+1}\left(\frac{I_{t+1}}{\eta \gamma I_{t}}-1\right) \frac{I_{t+1}^{2}}{\eta \gamma I_{t}^{2}}\right]
\end{aligned}
$$

\section{Estimation methodology, data and posterior parame- ter estimates}

To draw inferences from the two country model described above, I first log-linearize all the variables in the equations that define the model around their steady state and then estimate parameters values by using a Bayesian methodology (the log-linearized equations are provided in Appendix A). I choose this methodology since it has advantages over a more conventional calibration methodology, especially for models with nonstandard parameters and when there is uncertainty about the parameter values that govern shock processes. The methodology follows four basic steps (Fernandez-Villaverde and Rubio-Ramirez, 2004; Lubik and Schorfheide, 2005; Schorfheide, 2000 offer a more detailed description). The state space representation 
of the model is first converted to a reduced form state in its predetermined variables by following the methodology of Blanchard and Khan (1980). The residuals in the reduced form equations are the orthogonal shock innovations. In my baseline estimations, I assume that the innovations are not correlated across the two regions and thus the variance-covariance matrix of shock innovations is diagonal. Second, the predetermined variables are linked to the variables than can be observed (observables) via a measurement equation. Third, these observable variables are combined with a prior distribution of the parameter values to form a likelihood function by using a Kalman filter. Fourth, a posterior density function is obtained as the product of this likelihood function and the prior density function of the parameters. Finally, the parameter values that maximize the posterior density function are estimated by using a Markov Chain Monte Carlo simulation.

To estimate the model I use 21 quarterly data series/observables since there is a total of 21 shocks (10 shocks for each region and a common depreciation shock) in the model and the number of observables cannot exceed the number of shocks (data sources and definitions are provided in Appendix B). The 10 data series for each region are the gross domestic product, consumption and investment expenditures, import price index, GDP deflator, interbank short-term interest rate, corporate bond yield, wage rate, number of employed, stock market index. The common variable is the U.S. dollar per Euro nominal exchange rate. Each series is seasonally adjusted, demeaned and log-differenced (except for the interest rate and the corporate bond yields that are linearly detrended. The sample period is 1998Q1 to 2013Q4.

Some of the parameters in the model can be computed from the steady state values of state variables that can in turn be estimated by the mean values of the observable variables. Since the observables are demeaned, however, these parameter values cannot be estimated. These parameter values are instead calibrated to fixed values throughout the estimations. The time discount parameter, $\tilde{\beta}$, is set equal to 0.995 , implying a 2 percent annualized real interest rate. The intertemporal elasticity parameter, $\sigma$, is set equal to 1 so that there is unit elasticity. The population and per-capital output growth rate parameters, $\eta$ and $\gamma$, are 
set equal to 1.0025 and 1.005, implying a 1 percent and 2 percent annualized growth rate of population and output along the balanced growth path. The share of capital income and the depreciation rate parameters, $\alpha$ and $\delta$, are fixed to the standard values of 0.3 and 0.0025 , respectively. The price and wage mark-up parameters, $\phi_{p}$ and $\phi_{w}$, are set equal to 1.25 and 1.5 respectively following Smets and Wouters (2007). The domestic consumption and investment share parameters, $\gamma_{c}$ and $\gamma_{i}$, take the values of 0.9 implying a 10 percent of imports in the steady state. The entrepreneurial survival rate, $\gamma_{e}$, is set equal to usual value of 0.97 so that there is a 3 percent chance that the entrepreneurs will not survive. The level parameter, $\xi$, is set equal to $\xi=\frac{(1-\alpha)}{\phi_{w}(1-\lambda / \gamma)(C / Y)}$ to ensure that labor supply is equal to 1 at the steady-state.

The prior distributions of the parameters, reported in Tables 1 and 2, are formulated based on the findings of micro and macro-econometric studies and logical restrictions (such as restricting some priors to a positive support). These distributions are similar to those in the literature (Smets and Wouters, 2007 and Gilchrist et al., 2009) and their description is thus deferred to Appendix B. The posterior estimates reported in Table 1 and 2 are, in general, considerably different from their prior mean values indicating that the data are informative. Comparing across the two areas, I find that while the structural parameter estimates are similar, elasticity of substitution between home and foreign consumption goods, investment adjustment costs and import price adjustment parameter estimates are larger for the Euro Area. A noteworthy observation here is that the posterior mean values of the parameter governing the leverage elasticity of risk premium, $\chi$, are not only low compared to its prior mean but also compared to the commonly used and estimated values in the literature.

\section{Inferences from the baseline estimation}

The U.S. and Euro Area macroeconomic responses to various U.S. shocks (a one standard deviation shock) are presented in Figure $2{ }^{4}$ The responses of U.S. variables are significant

\footnotetext{
${ }^{4}$ I use Dynare to estimate the model and compute post-estimation statistics.
} 
and mostly consistent with those obtained from Vector Auto Regressive (VAR) analyses (e.g. Gali, 1999; Francis and Ramey, 2005; Christiano et al., 2001; Peersman and Smets, 2003). In response to a positive productivity shock, for example, employment and inflation drop, prompting a decrease in interest rates and an increase in consumption and investment demand. The drop in inflation here is amplified by habit formation and inflation adjustment costs. The three demand shocks (consumption, investment and government expenditure) have the opposite effect on employment and inflation. The crowding out of investment caused by positive consumption and government expenditure shocks generates lower credit spreads and mitigates the adverse effects of the shock on demand. Turning to cost-push shocks, the responses to positive wage and price mark-up shocks are similar except for labor since the two shocks have asymmetric effects on the intratemporal constraint that consumers face. Amongst the three financial shocks, net worth shocks have the most persistent and the largest effect on output. A positive shock to credit spreads generates a policy conflict by causing an increase in inflation and a drop in output at the same time. The U.S. macroeconomic variables in Figure 3 demonstrate a similar response to Euro Area shocks.

For my paper, the more central observations in Figures 2 and 3 are the mostly small and insignificant responses to foreign shocks. U.S. (Euro Area) responses to Euro Area shocks (U.S. shocks), especially when compared with the responses to U.S. shocks (Euro Area shocks), are small and insignificant as indicated by the 90 percent confidence intervals. These findings are consistent with the model moments in Table 3 that indicate a low macroeconomic correlation across the two regions. The baseline model, though not perfect, does a much better job of replicating the moments of domestic data. Similarly in Figure 4, Euro Area shocks and U.S. shocks have a low share in the historical decompositions of U.S. and Euro area output, respectively. The evidence suggests that while demand and financial shocks are the main determinants of output fluctuations, with demand shocks having a larger share (especially in the U.S.), and that cost-push, productivity and exchange rate shocks have a smaller impact. ${ }^{5}$

\footnotetext{
${ }^{5}$ For example in the U.S., the absolute values of the demand shock contributions when averaged across
} 
Therefore, the baseline formulation that connects the two regions through only trade in goods and risk-free bonds fails to account for the macroeconomic integration that is observed in the data.

\section{Common shocks and cross-regional shock transmis- sion}

In this section, I make two main changes to the baseline model to improve its performance along the cross-regional dimension and to identify the source of macroeconomic integration. First, I reconfigure each shock in the model to include a component common to both regions. Let $s_{t}^{c}$ and $s_{t}^{i d}$ denote the common component and the country specific component of shock $s$, respectively, then the expression for shock $s$ at time $t$ in this new formulation is given by, $s_{t}=s_{t}^{c} s_{t}^{i d} \cdot{ }^{6}$ After making this change and estimating the model, I assess the contribution of each common shock to the comovement of the main macroeconomic variables.

Second, I allow each shock to be correlated across the two regions (so that U.S. consumption shock is correlated with the Euro Area consumption shock and U.S. investment shock is correlated with the Euro Area investment shock, etc.). I then use the estimated values of the correlation coefficients in various post-estimation computations (for example when measuring impulse responses, historical and forecast error variance decompositions). There are two differences between the impact that common and correlated shocks have on model dynamics. First, while common shocks affect both regions symmetrically, with correlated shocks the relative impact depends on the sign and the magnitude of the correlation coefficient. Second, a Cholesky ordering is used as an identification scheme when the shocks are correlated across the two regions. While this strategy allows the model to generate the higher levels of

the sample period are approximately 2 and 4 times the contributions of financial and cost-push/productivity shocks, respectively.

${ }^{6}$ I also estimated a model with a looser parameterization where common and the country specific shocks have different shares in the composite shock function and these shares are different for each region. The results were similar and are available if requested. 
cross-country correlation, the drawback is that it relies on an unrealistic restriction. More specifically, if U.S. shocks are ordered first, as in my estimations, Euro Area shocks have an impact on the U.S. economy only with a lag, while U.S. shocks have a contemporaneous effect.

\subsection{Results from the model with common shocks}

Figures 5 and 6 display the historical decompositions of U.S. and Euro Area output that are obtained from the model with the common shock specification. The central finding here is the large share of common shocks. While foreign shocks have a small impact in both countries, common shocks have been as important as domestic shocks. Breaking down the contribution of common shocks by type, I find that demand shocks and financial shocks have the largest share with net worth and investment shocks making the largest contributions to the fluctuations of output in both countries. Consistent with the inferences from the historical decompositions, the common shock specification permits a better match between international data and the model. Specifically, the cross-country model moments, reported in column 3 of Table 3, are much closer to the data moments compared to the baseline results. This improvement, moreover, is not at the expense of the model's ability to match domestic moments as the disparity between the moments reported in columns 6 and 7 and data moments are similar. Notice that under the common shock specification, and as indicated in Table 1, the estimated mean value of the leverage elasticity parameter is higher compared to its value under the baseline specification suggesting that the shock transmission between the financial and the real sectors in both countries can be stronger with common shocks. A comparison of columns 3 and 4 with column 7 in Table 2 reveals that the persistence and standard deviations of the common shocks are similar, though not identical, to the corresponding values for the country specific shocks (for example, common investment shocks have higher persistence and lower standard deviation).

Forecast error variance decompositions in Table 4 demonstrate the importance of common 
shocks for international business cycles. These decompositions, measured as the contribution of each shock to the variance decomposition of total forecast errors, are computed for 4 different forecast horizons and for each endogenous variable the sum of the columns add up to 1. The contributions of common shocks are often comparable to region-specific shocks and for some variables, especially the financial variables, common shocks appear to be a more important determinant of volatility. While the fluctuations of output, investment and consumption are mainly driven by demand shocks, fluctuations of labor and the inflation variables are driven by cost-push and productivity shocks. Demand and cost-push/productivity shocks make a small contribution to the fluctuations of financial variables, especially for the U.S. net worth and credit spread variables, and the findings suggest that the channel of transmission from the financial sector to the real economy is stronger compared to its strength in the reverse direction. The contributions of financial shocks increase with the forecast horizon for all the variables except interest rates. Cost-push/productivity shocks become a more important determinant of interest rate volatility at longer horizons.

\subsection{Results from the model with correlated shocks}

I proceed by assessing the findings from the model where each pair of shock (U.S. and the Euro Area shock) is correlated. Table 5 compares the forecast error variance decompositions, aggregated at the regional level, across different model specifications for two forecast horizons. As expected, the transmission between the two regions becomes stronger when shocks are allowed to be correlated. While region-specific shocks remain the primary determinants, cross-regional transmission is large and certainly not negligible for all the variables. This is consistent with the size of the correlation coefficients reported in the column of Table 2 . Comparing across models, however, I observe that the contributions of common shocks to U.S. variables reported in columns 6 and 7 are mostly larger compared to the strength of the regional transmission suggested by the results in columns 3 and $4 .^{7}$ Consistent with earlier

\footnotetext{
${ }^{7}$ Ordering Euro Area shocks first produces similar results.
} 
results, the contribution of Euro Area shocks are negligible in the baseline model and in the model with common shocks. ${ }^{8}$

I obtain a more revealing set of evidence for the relative importance of common shocks when I include these shocks and allow for shock correlation simultaneously. The results in the last 3 columns of Table 5, for example, indicate that common shocks generally explain a considerably larger share of the macroeconomic volatility, especially for U.S. variables and the longer forecast horizon, compared to the share explained by the cross-country transmission of shocks (reported in columns 8 and 9 for Euro Area and U.S. variables, respectively). While common shocks have the largest impact on investment and net worth volatility, international transmission is a more important determinant of credit spread volatility. I should mention here that the relatively large impact of U.S. shocks on Euro Area net worth volatility is partially due to the ordering of the shocks.

Consistent with the inferences from Table 5, the international moments obtained from the model with common shocks and shock correlation (reported in the fourth column of Table 3) do not reveal a major improvement in the model's ability to match data moments. Similarly, allowing for shock correlation in the model with common shocks does not improve the model's marginal likelihood (in fact, the marginal likelihood computed using the Laplace approximation drops from 4029.5 to 4025.5$)$. The estimated values of the correlation coefficients corresponding to the model with common shocks and shock correlation (reported in Table 2) are also smaller for most shocks compared to the model with only correlated shocks.

A comparison of the impulse responses reported in Figure 7 across the different models points in the same direction. The U.S. output responses to common shocks are much higher than the responses to Euro Area shocks and allowing for shock correlation does not always amplify the responses to common shocks and if it does, the amplification is not large. The same observation can be made for the Euro Area output responses in the bottom panel of the

\footnotetext{
${ }^{8}$ In Dynare, when shocks are correlated, the share of a foreign shock is added to the corresponding domestic variable's share in the historical decomposition computations. These decompositions, therefore, indicate a very small explanatory power of foreign shocks as in the baseline estimations.
} 
figure: allowing for shock correlation does not have a significant and a unidirectional impact on the impulse responses to common shocks. While Euro Area output responses reveal a large effect of U.S. shocks, it is not clear that this transmission is stronger than the responses to common shocks. ${ }^{9}$

Notice that in the model with common shocks (and in the model with common and correlated shocks) the number of observables is less than the number of shocks. With this feature, it then becomes questionable whether one can strongly identify the parameters of the model and whether the model is a good representation of the true data generating process. To test for the presence of identification problems, I use the methodology of Iskrev (2010) that computes the analytical derivatives of the observables with respect to the estimated values of the parameters to construct the Fisher information matrix. Under weak identification, this matrix is either singular or nearly-singular. I find that for all 4 models, the Fisher information matrix is full rank and thus the estimation methodology is able to identify the structural parameters and the parameters governing the shock processes.

\section{Conclusion}

Estimated New Keynesian DSGE models have become an important policy analysis and forecasting tool for most central banks. In this paper, I demonstrated a shortcoming of these models along the international dimension by revealing their inability to match the high degree of macroeconomic integration between the U.S. and the Euro Area.

Reconfiguring the shock processes in the model, I found that shocks that are common to both regions, more so than shock transmission from one region to the other, account for the comovements of macroeconomic variables that the baseline model cannot replicate and that common demand and financial shocks are more important determinants of the symmetric responses of the two economies compared to exchange rate, and common productivity and

\footnotetext{
${ }^{9}$ I find that the results are reversed, i.e., the U.S. responses to Euro Area shocks are large, when Euro Area shocks are ordered ahead of U.S. shocks.
} 
cost-push shocks.

Notice that the different shock specifications that I introduce in the model do not enhance its ability to provide more accurate forecasts and policy predictions since the shocks in the model, by definition, are not related to the endogenous variables. The results do, however, uncover the most important sources of macroeconomic integration and provide a guidance for future enhancements in the empirical relevance of open economy models and their forecasting performance. According to the results, these enhancements would be most effective if they focus on mechanisms that can generate symmetric responses of demand and financial side variables and can, therefore, decrease the importance of exogenous shocks and shock correlations.

By using Euro Area and U.S. data to estimate the two-country model, I was able to investigate a large share of global economic activity and consider two regions that are similar in size. As a result of this approach, however, the inferences in this paper were drawn from a relatively short sample period (as Euro Area data were only available after 1995). It would be interesting, therefore, to use data from other country pairs that span longer periods and identify how the primary sources of macroeconomic integration (across a broader set of countries) have evolved over time.

\section{References}

[1] Alpanda, S., Aysun, U., 2014. "International transmission of financial shocks in an estimated DSGE model," Journal of International Money and Finance, 47, 21-55.

[2] Ambler, S., Cardia, E., Zimmerman, C., 2002. "International Transmission of the Business Cycle in a Multi-Sector Model," European Economic Review, 46, 273-300.

[3] Backus, D., Kehoe, P., Kydland, F., 1992. "International real business cycles," Journal of Political Economy, 101, 745-775. 
[4] Bernanke, B. S., Gertler, M., Gilchrist, S., 1999. "The Financial Accelerator in a Quantitative Business Cycle Framework," in Handbook of Macroeconomics vol. 1C, ed. by J. B. Taylor and M. Woodford, 1341-93. Amsterdam: Elsevier Science, North-Holland.

[5] Blanchard, O., Kahn, C., 1980. "The Solution of Linear Difference Models under Rational Expectations," Econometrica, 48, 1305-1311.

[6] Canova F., de Nicolo, G., 2003. "On the sources of business cycles in the G-7", Journal of International Economics 59, 77-100.

[7] Christiano, L.J., Eichenbaum, M., Evans, C.L., 2001. "Nominal Rigidities and the Dynamic Effects of a Shock to Monetary Policy," Working Paper no. 8403 (July), NBER, Cambridge, MA.

[8] Crucini, M., Kose, A., Otrok, C., 2011. "What are the driving forces of international business cycles?" Review of Economic Dynamics 14, 156-175.

[9] Devereux, M., Gregory, A., Smith, G., 1992. "Realistic cross-country consumption correlations in a two-country, equilibrium business cycle model," Journal of International Money and Finance 11, 3-16.

[10] Devereux, M.B., Yetman, J., 2010. "Leverage constraints and the international transmission of shocks," Journal of Money, Credit and Banking 42, 71-105.

[11] Dixit, A. K., Stiglitz, J.E., 1977. "Monopolistic Competition and Optimum Product Diversity,"American Economic Review, 67(3), 297-308.

[12] Elliott, G., Fatas, A., 1996. "International business cycles and the dynamics of the current account," European Economic Review, 40(2), 361-387.

[13] Fernandez-Villaverde, J., 2010. "Fiscal Policy in a Model with Financial Frictions," American Economic Review: Papers \& Proceedings, 100, 35-40. 
[14] Fernandez-Villaverde J., Rubio-Ramirez J., 2004. "Comparing dynamic equilibrium models to data: a Bayesian approach," Journal of Econometrics, 123, 153-187.

[15] Francis, N., Ramey, V., 2005. "Is the technology-driven real business cycle hypothesis dead? Shocks and aggregate fluctuations revisited," Journal of Monetary Economics, 52(8), 1379-1399.

[16] Gali, J., 1999. "Technology, Employment, and the Business Cycle: Do Technology Shocks Explain Aggregate Fluctuations?" American Economic Review, 89(1), 249-271.

[17] Gilchrist, S., Ortiz, A., Zakrajsek, E., 2009. "Credit Risk and the Macroeconomy: Evidence from an Estimated DSGE Model," mimeo, Boston University.

[18] Heathcote, J., Perri, F., 2002), "Financial Autarky and International Business Cycles", Journal of Monetary Economics, April, 49/3, pp.601-627.

[19] Iskrev, Nicolay, "Local Identification in DSGE Models," Journal of Monetary Economics, 57, 2010, 189-210.

[20] Jeon, B.N., Olivero, M.P., Wu, J., 2013. "Multinational banking and the international transmission of financial shocks: Evidence from foreign bank subsidiaries," Journal of Banking \& Finance, 37(3), 952-972.

[21] Kehoe, P. and F. Perri, 2002. "International Business Cycles with Endogenous Incomplete Markets," Econometrica, 70(3), 907-928.

[22] Keller, W., 2004. "International Technology Diffusion," Journal of Economic Literature, $42,752-782$.

[23] Kollman, R., 1996. "Incomplete Asset Markets and the Cross-Country Consumption Correlation Puzzle," Journal of Economic Dynamics and Control, 20, 945-961. 
[24] Kollmann, R., Enders, Z., Muller, G., 2011. "Global banking and international business cycles," European Economic Review, 55, 407-426.

[25] Kose, A., Yi, K., 2001. "International Trade and Business Cycles: Is Vertical Specialization the Missing Link?" American Economic Review, Papers and Proceedings, Vol. 91, pp. $371-375$.

[26] Kose, A., Otrok, C., Whiteman, C.H., 2008. "Understanding the evolution of world business cycles," Journal of International Economics 75(1), 110-130.

[27] Lubik, T., Schorfheide, F., 2005. "A Bayesian Look at New Open Economy Macroeconomics," in Mark Gertler and Kenneth Rogoff (eds.) NBER Macroeconomics Annual 2005, MIT Press, Cambridge, MA.

[28] Obstfeld, M., Rogoff, K., 2001. "The Six Major Puzzles in International Macroeconomics: Is there a Common Cause?" NBER Macroeconomics Annual 2000, 339-389.

[29] Peersman, G., Smets, F., 2003. "The monetary transmission mechanism in the euro area: evidence from VAR analysis," in Angeloni I, A Kashyap and B Mojon (eds.), Monetary policy transmission in the euro area, Cambridge University Press, 56-74.

[30] Ravn, M.O., Mazzenga, E., 2004. "International Business Cycles: The Quantitative Role of Transportation Costs," Journal of International Money and Finance, 23, 645-671.

[31] Schmitt-Grohe, S., 1998. "The International Transmission of Economic Fluctuations: Effects of U.S. Business Cycles on the Canadian Economy,” Journal of International Economics, 44, 257-287.

[32] Schorfheide, F., 2000. "Loss function-based evaluation of DSGE models," Journal of Applied Econometrics, 15(6), 645-670.

[33] Smets, F., Wouters, R., 2007. "Shocks and Frictions in US Business Cycles: A Bayesian DSGE Approach," American Economic Review, 97, 586-606. 
[34] Stockman, A., Tesar, L., 1995. "Tastes and technology in a two-country model of the business cycle: explaining international comovements,". American Economic Review 85, $168-185$.

[35] Zimmermann, C., 1997. "International Real Business Cycles Among Heterogeneous Countries," European Economic Review, 41, 319-55. 


\section{Appendix A. The log-linearized model}

In this Appendix I report the log-linearized equations of the model. The variables in these equations, denoted by lower case letters, represent deviations from steady state values and variables without time subscripts represent the steady state values. The equations that form the model can be classified under four general categories.

Demand for domestic and foreign consumption and investment goods:

$$
\begin{gathered}
c_{t}=\frac{\lambda / \gamma}{1+\lambda / \gamma} c_{t-1}+\frac{1}{1+\lambda / \gamma} E_{t} c_{t+1} \\
+\frac{(1-\lambda / \gamma)}{\sigma(1+\lambda / \gamma)}\left[(\sigma-1) \xi\left(l_{t}-E_{t} l_{t+1}\right)-\left(r_{t}-E_{t} \pi_{t+1}\right)\right]+\varepsilon_{c, t} \\
c_{t}=\gamma_{c} c_{h, t}+\left(1-\gamma_{c}\right) c_{f, t} \\
c_{h, t}-c_{f, t}=\lambda_{c}\left(p_{f, t}-p_{h, t}\right) \\
i_{t}=\frac{1}{1+\tilde{\beta}} i_{t-1}+\frac{1}{1+\tilde{\beta}} E_{t} i_{t+1}+\frac{1}{(1+\tilde{\beta}) \varphi}\left(q_{t}-p_{i, t}\right)+\varepsilon_{i, t} \\
i_{t}=\gamma_{i} i_{h, t}+\left(1-\gamma_{i}\right) i_{f, t} \\
i_{h, t}-i_{f, t}=\lambda_{i}\left(p_{f, t}-p_{h, t}\right)
\end{gathered}
$$

Domestic and foreign goods price and wage inflation:

$$
\begin{gathered}
\pi_{t}=\gamma_{c} \pi_{h, t}+\left(1-\gamma_{c}\right) \pi_{f, t} \\
p_{i, t}=\gamma_{i} p_{h, t}+\left(1-\gamma_{i}\right) p_{f, t} \\
\pi_{w, t}-\iota_{w} \pi_{t-1}=\tilde{\beta}\left(E_{t} \pi_{w, t+1}-\iota_{w} \pi_{t}\right)- \\
\frac{\left(1-\xi_{w}\right)\left(1-\xi_{w} \tilde{\beta}\right)}{6 \xi_{w}}\left\{w_{t}-\left[\sigma_{l} l_{t}+\frac{1}{1-\lambda / \gamma}\left(c_{t}-\frac{\lambda}{\gamma} c_{t-1}\right)\right]\right\}+\varepsilon_{w, t}
\end{gathered}
$$




$$
\begin{gathered}
\pi_{w, t}=w_{t}-w_{t-1}+\pi_{t} \\
\pi_{h, t}=\frac{\left(\iota_{h} \pi_{h, t-1}+\tilde{\beta} \pi_{h, t+1}\right)}{\left(1+\iota_{h} \tilde{\beta}\right)}-\frac{\left(1-\xi_{h}\right)\left(1-\tilde{\beta} \xi_{h}\right)}{3.5 \xi_{h}\left(1+\iota_{h} \tilde{\beta}\right)}\left[p_{h, t}+\varepsilon_{a, t}+\alpha\left(z_{t}+k_{t}-l_{t}\right)-w_{t}\right]+\varepsilon_{h, t} \\
\pi_{h, t}-\pi_{t}=p_{h, t}-p_{h, t-1} \\
\pi_{f, t}=\frac{\iota_{f}}{1+\iota_{f} \tilde{\beta}} \pi_{f, t-1}+\frac{\tilde{\beta}}{1+\iota_{f} \tilde{\beta}} \pi_{f, t+1}-\frac{\left(1-\xi_{f}\right)\left(1-\xi_{f} \tilde{\beta}\right)}{3.5 \xi_{f}\left(1+\iota_{f} \tilde{\beta}\right)}\left[p_{f, t}-\operatorname{rer}_{t}-p_{h, t}^{*}\right]+\varepsilon_{f, t}
\end{gathered}
$$

Production and market clearing:

$$
\begin{gathered}
y_{t}=\phi_{p}\left[\varepsilon_{a, t}+\alpha\left(z_{t}+k_{t}\right)+(1-\alpha) l_{t}\right] \\
m p k_{t}=-\left(z_{t}+k_{t}-l_{t}\right)+w_{t} \\
z_{t}=m p k_{t} / \varpi \\
k_{t}=((1-\delta) / \eta \gamma) k_{t-1}+(1-(1-\delta) / \eta \gamma)\left(i_{t}+(1+\tilde{\beta}) \varphi \varepsilon_{i, t}\right) \\
r_{k, t}=((1-\delta) \tilde{\beta} / \eta \gamma) q_{t}+(1-(1-\delta) \tilde{\beta} / \eta \gamma) m p k_{t}-q_{t-1} \\
y_{t}=\gamma_{c} \frac{C}{Y} c_{h, t}+\gamma_{i} \frac{I}{Y} i_{h, t}+\frac{G}{Y} g_{t}+\left(1-\gamma_{c}\right) \frac{C}{Y} c_{f, t}^{*}+\left(1-\gamma_{i}\right) \frac{I}{Y} i_{f, t}^{*}
\end{gathered}
$$

\section{The financial market:}

$$
\begin{gathered}
E_{t} r_{k, t+1}=r_{t}-E_{t} \pi_{t+1}+\chi\left(q_{t}+k_{t}-n_{t}\right)+\varepsilon_{k, t} \\
n_{t}=\gamma_{e} r_{k}\left(r_{k, t}+n_{t-1}\right) / \gamma \eta+\varepsilon_{n, t} \\
r_{t}=\rho r_{t-1}+(1-\rho)\left[r_{\pi} \pi_{t}+r_{y} y_{t}+r_{\Delta y}\left(y_{t}-y_{t-1}\right)\right]+\varepsilon_{r, t} \\
r e r_{t}-r e r_{t-1}=d_{t}+\pi_{t}^{*}-\pi_{t}
\end{gathered}
$$




\section{Appendix B. Prior Distributions and Posterior Estimates}

The prior distributions for the parameters are provided in Table 1 for home-country and foreign-country parameters. The priors here are very similar to Smets and Wouters (2007) and Gilchrist et al. (2009) for the parameters that are not related to the open economy features of the model. The habit parameter, $\lambda$, has a beta-distribution prior with a mean of 0.7 and a standard deviation of 0.1 . The parameter $\sigma_{l}$ has a normal prior with a mean of 2 (reflecting a Frisch-elasticity of labor supply of 0.5 ) and a standard deviation of 0.75 . The capacity utilization elasticity parameter, $\psi$, has a beta prior with mean 0.5 (which implies unit elasticity of utilization with respect to the marginal product of capital) and standard deviation 0.1. The investment adjustment-cost parameter, $\varphi$, has a normal prior with mean 4 and standard deviation 1.5. The Calvo parameters, $\xi_{h}, \xi_{f}$ and $\xi_{w}$, all have beta priors with mean 0.5 (i.e. an average of 2-quarter price and wage stickiness) and standard deviation 0.1. The price and wage indexation parameters, $\iota_{h}, \iota_{f}$ and $\iota_{w}$, have beta priors with a mean 0.5 and standard deviation of 0.15 . The price mark-up at the steady-state, $\phi_{p}$, is assumed to have a normal prior with mean 1.25 and standard deviation 0.1. As in Gilchrist et al. (2009), the elasticity of the external finance premium to leverage, $\chi$, is assumed to be beta-distributed with a mean of 0.07 and a standard deviation of 0.02 .

For the Taylor rule parameters, I assume that the prior for the long-run inflation reaction coefficient, $r_{\pi}$, has a normal distribution with a mean of 1.5 and standard deviation 0.25. Similarly, the long-run reaction coefficient on output and output growth, $r_{y}$ and $r_{\Delta y}$, have normal distributions with mean 0.25 and standard deviation 0.12 . The prior for the interest rate smoothing parameter, $\rho$, has a normal distribution with mean 0.75 and standard deviation 0.1 .

The priors for the autoregressive and moving average terms in all shocks have beta distributions with mean 0.5 and standard deviation 0.2 . The priors for the standard deviations of all the shocks are also fairly uninformative, with inverse-gamma distributions with mean $0.5 \%$ and infinite variance. 
Table 1. Prior distributions and posterior estimates of structural parameters

\begin{tabular}{|c|c|c|c|c|c|c|c|c|c|}
\hline & \multirow[b]{3}{*}{ Prior Densities } & \multicolumn{8}{|c|}{ Posterior Means } \\
\hline & & \multicolumn{2}{|c|}{ Baseline } & \multicolumn{2}{|c|}{ Common shocks } & \multicolumn{2}{|c|}{ Correlated shocks } & \multicolumn{2}{|c|}{$\begin{array}{l}\text { Common shocks and } \\
\text { correlated shocks }\end{array}$} \\
\hline & & U.S. & Euro Area & U.S. & Euro Area & U.S. & Euro Area & U.S. & Euro Area \\
\hline$\chi$ & $\mathrm{B}(0.07,0.02)$ & 0.0097 & 0.0082 & 0.0187 & 0.0123 & 0.0111 & 0.0088 & 0.0107 & 0.0089 \\
\hline$\lambda$ & $\mathrm{B}(0.7,0.1)$ & 0.9541 & 0.9760 & 0.9592 & 0.9817 & 0.9337 & 0.9778 & 0.9496 & 0.9657 \\
\hline$\sigma_{l}$ & $\mathrm{~N}(2,0.75)$ & 1.4973 & 1.6627 & 1.5105 & 1.7456 & 0.8353 & 1.6163 & 1.3658 & 2.0104 \\
\hline$\psi$ & $\mathrm{B}(0.5,0.2)$ & 0.1505 & 0.1998 & 0.1448 & 0.2425 & 0.1675 & 0.1617 & 0.1501 & 0.2220 \\
\hline$\varphi$ & $\mathrm{N}(4,1.5)$ & 6.3842 & 9.1693 & 7.4639 & 9.2109 & 8.4759 & 8.3567 & 7.6182 & 9.9597 \\
\hline$l_{h}$ & $\mathrm{~B}(0.5,0.15)$ & 0.6141 & 0.2452 & 0.5803 & 0.1508 & 0.4833 & 0.2480 & 0.3380 & 0.1453 \\
\hline$l_{f}$ & $\mathrm{~B}(0.5,0.15)$ & 0.2948 & 0.2698 & 0.1752 & 0.2732 & 0.2533 & 0.2771 & 0.1685 & 0.3293 \\
\hline$l_{w}$ & $\mathrm{~B}(0.5,0.15)$ & 0.1722 & 0.4014 & 0.2431 & 0.2524 & 0.0941 & 0.4175 & 0.0988 & 0.3140 \\
\hline$\xi_{h}$ & $\mathrm{~B}(0.5,0.1)$ & 0.8150 & 0.8438 & 0.8003 & 0.8246 & 0.8177 & 0.8196 & 0.8132 & 0.8445 \\
\hline$\xi_{f}$ & $\mathrm{~B}(0.5,0.1)$ & 0.2451 & 0.6649 & 0.4163 & 0.5527 & 0.2621 & 0.6855 & 0.3578 & 0.6583 \\
\hline$\xi_{w}$ & $\mathrm{~B}(0.5,0.1)$ & 0.8626 & 0.8097 & 0.8378 & 0.8190 & 0.8208 & 0.8363 & 0.8259 & 0.7834 \\
\hline$\lambda_{c}$ & $G(1,0.2)$ & 0.2008 & 0.9389 & 0.1643 & 0.9633 & 0.2345 & 0.8769 & 0.2095 & 0.8712 \\
\hline$\lambda_{i}$ & $\mathrm{G}(0.25,0.2)$ & 0.1654 & 0.2230 & 0.2547 & 0.1987 & 0.2390 & 0.2436 & 0.1635 & 0.3732 \\
\hline$\rho$ & $\mathrm{N}(0.75,0.1)$ & 0.5981 & 0.6217 & 0.6288 & 0.5308 & 0.6648 & 0.6448 & 0.6574 & 0.6583 \\
\hline$r_{\pi}$ & $\mathrm{N}(1.5,0.25)$ & 1.5037 & 1.1688 & 1.3153 & 1.1024 & 1.4893 & 1.1552 & 1.3711 & 1.0664 \\
\hline$r_{y}$ & $\mathrm{~N}(0.25,0.12)$ & 0.0286 & 0.0337 & 0.0367 & 0.0393 & 0.0316 & 0.0391 & 0.0382 & 0.0426 \\
\hline$r_{\Delta y}$ & $\mathrm{~N}(0.25,0.12)$ & 0.2557 & 0.3494 & 0.1803 & 0.5111 & 0.1866 & 0.6648 & 0.2777 & 0.5406 \\
\hline
\end{tabular}

Note: The table displays the prior distributions and the posterior mean estimates of model parameters. The prior distributions denoted by B, N and G are the Beta, Gamma and Normal distributions, respectively. 
Table 2. Prior distributions and posterior estimates of shock process parameters

\begin{tabular}{|c|c|c|c|c|c|c|c|c|c|c|c|}
\hline & \multirow[b]{3}{*}{ Prior Density } & \multicolumn{8}{|c|}{$\begin{array}{l}\text { Posterior mean values of country specific shock parameters by } \\
\text { model }\end{array}$} & \multicolumn{2}{|c|}{$\begin{array}{c}\text { Posterior mean values } \\
\text { of common shock } \\
\text { parameters by model }\end{array}$} \\
\hline & & \multicolumn{2}{|c|}{ Baseline } & \multicolumn{2}{|c|}{$\begin{array}{c}\text { Common } \\
\text { shocks }\end{array}$} & \multicolumn{2}{|c|}{$\begin{array}{l}\text { Correlated } \\
\text { shocks }\end{array}$} & \multicolumn{2}{|c|}{$\begin{array}{l}\text { Common } \\
\text { shocks and } \\
\text { correlated } \\
\text { shocks }\end{array}$} & \multirow[t]{2}{*}{$\begin{array}{l}\text { Common } \\
\text { shocks }\end{array}$} & \multirow{2}{*}{$\begin{array}{l}\text { Common } \\
\text { shocks and } \\
\text { correlated } \\
\text { shocks }\end{array}$} \\
\hline & & U.S. & $\begin{array}{l}\text { Euro } \\
\text { Area }\end{array}$ & U.S. & $\begin{array}{l}\text { Euro } \\
\text { Area }\end{array}$ & U.S. & $\begin{array}{l}\text { Euro } \\
\text { Area }\end{array}$ & U.S. & $\begin{array}{l}\text { Euro } \\
\text { Area }\end{array}$ & & \\
\hline \multicolumn{12}{|c|}{$\underline{\text { Persistence parameters }}$} \\
\hline consumption & $\mathrm{B}(0.5,0.2)$ & 0.3995 & 0.4038 & 0.2464 & 0.1948 & 0.4173 & 0.3583 & 0.2723 & 0.2640 & 0.3685 & 0.2646 \\
\hline investment & $\mathrm{B}(0.5,0.2)$ & 0.6541 & 0.4573 & 0.4742 & 0.1898 & 0.6002 & 0.4406 & 0.4881 & 0.2752 & 0.6916 & 0.5923 \\
\hline government exp. & $\mathrm{B}(0.5,0.2)$ & 0.9302 & 0.9161 & 0.9073 & 0.9147 & 0.8730 & 0.9405 & 0.8634 & 0.9385 & 0.6328 & 0.5054 \\
\hline productivity & $\mathrm{B}(0.5,0.2)$ & 0.8022 & 0.7355 & 0.7148 & 0.7132 & 0.6922 & 0.7213 & 0.7083 & 0.7034 & 0.7103 & 0.7120 \\
\hline interest rate & $\mathrm{B}(0.5,0.2)$ & 0.2406 & 0.1042 & 0.2208 & 0.0661 & 0.1514 & 0.1018 & 0.1542 & 0.1501 & 0.1748 & 0.1719 \\
\hline price, domestic & $\mathrm{B}(0.5,0.2)$ & 0.0293 & 0.0396 & 0.1157 & 0.1579 & 0.0583 & 0.0505 & 0.1994 & 0.0822 & 0.0580 & 0.0561 \\
\hline price, foreign & $\mathrm{B}(0.5,0.2)$ & 0.9716 & 0.6776 & 0.8401 & 0.8309 & 0.9697 & 0.6154 & 0.9143 & 0.6763 & 0.8347 & 0.6260 \\
\hline wage & $\mathrm{B}(0.5,0.2)$ & 0.4192 & 0.2154 & 0.3071 & 0.1520 & 0.4145 & 0.1466 & 0.2049 & 0.2296 & 0.2844 & 0.3074 \\
\hline credit spread & $\mathrm{B}(0.5,0.2)$ & 0.1374 & 0.3580 & 0.3520 & 0.3652 & 0.2166 & 0.3915 & 0.1735 & 0.3301 & 0.3312 & 0.4482 \\
\hline net worth & $\mathrm{B}(0.5,0.2)$ & 0.3153 & 0.1508 & 0.3940 & 0.1733 & 0.3023 & 0.2767 & 0.4154 & 0.2972 & 0.1460 & 0.2509 \\
\hline depreciation & $\mathrm{B}(0.5,0.2)$ & 0.8531 & & 0.8511 & & 0.8626 & & 0.8474 & & & \\
\hline \multicolumn{12}{|c|}{$\underline{\text { Shock standard deviations }}$} \\
\hline consumption & IG $(0.5 \%$, inf $)$ & 0.0016 & 0.0013 & 0.0015 & 0.0012 & 0.0017 & 0.0014 & 0.0019 & 0.0014 & 0.0012 & 0.0013 \\
\hline investment & IG $(0.5 \%$, inf $)$ & 0.0035 & 0.0039 & 0.0040 & 0.0040 & 0.0039 & 0.0044 & 0.0041 & 0.0036 & 0.0019 & 0.0021 \\
\hline government exp. & IG $(0.5 \%$, inf $)$ & 0.0198 & 0.0135 & 0.0203 & 0.0110 & 0.0240 & 0.0136 & 0.0221 & 0.0112 & 0.0040 & 0.0027 \\
\hline productivity & IG $(0.5 \%$, inf $)$ & 0.0051 & 0.0070 & 0.0048 & 0.0062 & 0.0059 & 0.0062 & 0.0053 & 0.0060 & 0.0017 & 0.0018 \\
\hline interest rate & IG $(0.5 \%$, inf $)$ & 0.0034 & 0.0033 & 0.0023 & 0.0023 & 0.0035 & 0.0037 & 0.0029 & 0.0031 & 0.0022 & 0.0021 \\
\hline price, domestic & IG $(0.5 \%$, inf $)$ & 0.0015 & 0.0016 & 0.0014 & 0.0013 & 0.0017 & 0.0016 & 0.0016 & 0.0013 & 0.0011 & 0.0012 \\
\hline price, foreign & IG $(0.5 \%$, inf $)$ & 0.0233 & 0.0083 & 0.0128 & 0.0036 & 0.0238 & 0.0079 & 0.0143 & 0.0021 & 0.0070 & 0.0077 \\
\hline wage & IG $(0.5 \%$, inf $)$ & 0.0012 & 0.0045 & 0.0014 & 0.0043 & 0.0012 & 0.0052 & 0.0012 & 0.0052 & 0.0012 & 0.0011 \\
\hline credit spread & IG $(0.5 \%$, inf $)$ & 0.0100 & 0.0187 & 0.0022 & 0.0108 & 0.0096 & 0.0172 & 0.0091 & 0.0165 & 0.0099 & 0.0029 \\
\hline net worth & IG $(0.5 \%$, inf $)$ & 0.0720 & 0.0906 & 0.0029 & 0.0509 & 0.0753 & 0.1027 & 0.0028 & 0.0458 & 0.0748 & 0.0667 \\
\hline depreciation & IG $(0.5 \%$, inf $)$ & 0.0039 & & 0.0054 & & 0.0040 & & 0.0055 & & & \\
\hline \multicolumn{12}{|c|}{$\underline{\text { Shock correlations }}$} \\
\hline consumption & $\mathrm{B}(0.5,0.2)$ & & & & & 0.5449 & & 0.3345 & & & \\
\hline investment & $\mathrm{B}(0.5,0.2)$ & & & & & 0.3970 & & 0.2293 & & & \\
\hline government exp. & $\mathrm{B}(0.5,0.2)$ & & & & & 0.2921 & & 0.1968 & & & \\
\hline productivity & $\mathrm{B}(0.5,0.2)$ & & & & & 0.1684 & & 0.1370 & & & \\
\hline interest rate & $\mathrm{B}(0.5,0.2)$ & & & & & 0.4982 & & 0.2707 & & & \\
\hline price, domestic & $\mathrm{B}(0.5,0.2)$ & & & & & 0.2049 & & 0.1807 & & & \\
\hline price, foreign & $\mathrm{B}(0.5,0.2)$ & & & & & 0.3492 & & 0.3762 & & & \\
\hline wage & $\mathrm{B}(0.5,0.2)$ & & & & & 0.1482 & & 0.1394 & & & \\
\hline credit spread & $\mathrm{B}(0.5,0.2)$ & & & & & 0.8659 & & 0.8837 & & & \\
\hline net worth & $\mathrm{B}(0.5,0.2)$ & & & & & 0.8657 & & 0.3085 & & & \\
\hline
\end{tabular}

Notes: The table displays the prior distributions and the posterior mean estimates of the parameters governing the shock processes. The prior distributions denoted by B and IG are the beta and inverse gamma distributions, respectively. Shock correlation values displayed at the bottom of the table represent the correlation coefficients of the shocks measured across the U.S. and the Euro Area. 
Table 3. Data versus model moments

\begin{tabular}{|c|c|c|c|c|c|c|c|c|c|c|}
\hline Cross-regional correlation & Data & $\begin{array}{c}\text { Baseline } \\
\text { model }\end{array}$ & $\begin{array}{c}\text { Common } \\
\text { shocks }\end{array}$ & $\begin{array}{c}\text { Common } \\
\& \\
\text { correlated } \\
\text { shocks }\end{array}$ & \multicolumn{2}{|c|}{ Country-specific moments } & Data & $\begin{array}{c}\text { Baseline } \\
\text { model }\end{array}$ & $\begin{array}{c}\text { Common } \\
\text { shocks }\end{array}$ & $\begin{array}{c}\text { Common } \\
\& \\
\text { correlated } \\
\text { shocks }\end{array}$ \\
\hline$\rho\left(y, y^{*}\right)$ & 0.573 & 0.111 & 0.413 & 0.521 & \multirow[t]{10}{*}{ U.S. } & $\rho(y, i)$ & 0.754 & 0.589 & 0.575 & 0.555 \\
\hline$\rho\left(c, c^{*}\right)$ & 0.599 & 0.008 & 0.554 & 0.635 & & $\rho(y, l)$ & 0.471 & 0.676 & 0.656 & 0.653 \\
\hline$\rho(i, i *)$ & 0.613 & 0.039 & 0.588 & 0.607 & & $\sigma(c) / \sigma(y)$ & 0.812 & 0.865 & 0.874 & 0.915 \\
\hline$\rho(l, l *)$ & 0.108 & 0.040 & 0.180 & 0.262 & & $\sigma(i) / \sigma(y)$ & 3.230 & 3.036 & 2.881 & 2.836 \\
\hline$\rho\left(\pi_{h}, \pi_{h}^{*}\right)$ & 0.320 & 0.020 & 0.306 & 0.408 & & $\sigma(l) / \sigma(y)$ & 0.736 & 1.220 & 1.204 & 1.199 \\
\hline$\rho\left(\pi_{f}, \pi_{f}^{*}\right)$ & 0.573 & 0.020 & 0.219 & 0.339 & & $\rho\left(y^{*}, i^{*}\right)$ & 0.898 & 0.666 & 0.628 & 0.624 \\
\hline$\rho\left(\pi_{w}, \pi_{w}^{*}\right)$ & 0.060 & -0.006 & 0.228 & 0.289 & & $\rho\left(y^{*}, l^{*}\right)$ & 0.368 & 0.475 & 0.463 & 0.462 \\
\hline$\rho\left(r k, r k^{*}\right)$ & 0.881 & -0.006 & 0.696 & 0.872 & & $\sigma\left(c^{*}\right) / \sigma\left(y^{*}\right)$ & 0.650 & 0.869 & 0.962 & 0.981 \\
\hline$\rho\left(n, n^{*}\right)$ & 0.864 & -0.002 & 0.835 & 0.832 & & $\sigma\left(i^{*}\right) / \sigma\left(y^{*}\right)$ & 2.389 & 3.360 & 3.190 & 3.211 \\
\hline$\rho\left(r, r^{*}\right)$ & 0.533 & 0.054 & 0.448 & 0.489 & & $\sigma(l *) / \sigma\left(y^{*}\right)$ & 1.077 & 1.764 & 1.693 & 1.722 \\
\hline
\end{tabular}

Notes: The table compares the moments of the endogenous variables obtained from the data to the posterior moments obtained from the models. 
Table 4. Forecast error variance decompositions, model with common shocks.

\begin{tabular}{|c|c|c|c|c|c|c|c|c|c|c|}
\hline \multicolumn{11}{|l|}{ forecast horizon = 1 quarter } \\
\hline & \multicolumn{3}{|c|}{ U.S. shocks } & \multicolumn{3}{|c|}{ Euro Area shocks } & \multicolumn{4}{|c|}{ Common shocks } \\
\hline U.S. endogenous variables & $\begin{array}{l}\text { Productivity } \\
\text { \& cost-push } \\
\text { shocks }\end{array}$ & $\begin{array}{c}\text { Demand } \\
\text { shocks }\end{array}$ & $\begin{array}{c}\text { Financial } \\
\text { shocks }\end{array}$ & $\begin{array}{l}\text { Productivity } \\
\text { \& cost-push } \\
\text { shocks }\end{array}$ & $\begin{array}{c}\text { Demand } \\
\text { shocks }\end{array}$ & $\begin{array}{l}\text { Financial } \\
\text { shocks }\end{array}$ & $\begin{array}{l}\text { Productivity } \\
\text { \& cost-push } \\
\text { shocks }\end{array}$ & $\begin{array}{l}\text { Demand } \\
\text { shocks }\end{array}$ & $\begin{array}{c}\text { Financial } \\
\text { shocks }\end{array}$ & $\begin{array}{l}\text { Exchange } \\
\text { rate shocks }\end{array}$ \\
\hline output & 0.20 & 68.90 & 0.87 & 0.71 & 0.14 & 0.01 & 1.33 & 20.69 & 7.01 & 0.16 \\
\hline consumption & 0.10 & 54.19 & 0.53 & 0.04 & 0.00 & 0.04 & 0.17 & 43.23 & 1.59 & 0.12 \\
\hline investment & 0.47 & 46.07 & 0.70 & 0.01 & 0.00 & 0.00 & 0.26 & 27.89 & 24.20 & 0.39 \\
\hline labor & 49.41 & 30.83 & 0.43 & 0.18 & 0.05 & 0.01 & 6.65 & 8.50 & 3.45 & 0.48 \\
\hline wage inflation & 47.18 & 7.04 & 0.60 & 0.21 & 0.01 & 0.18 & 35.16 & 8.73 & 0.65 & 0.24 \\
\hline net worth & 0.09 & 0.00 & 0.25 & 0.00 & 0.00 & 0.00 & 0.05 & 0.00 & 99.58 & 0.01 \\
\hline interest rates & 8.04 & 1.16 & 38.45 & 0.07 & 0.00 & 0.06 & 4.47 & 0.35 & 45.26 & 2.14 \\
\hline inflation, foreign goods & 43.04 & 0.12 & 0.70 & 1.85 & 0.08 & 0.82 & 30.43 & 0.04 & 0.22 & 22.69 \\
\hline inflation, domestic goods & 65.52 & 0.08 & 0.03 & 0.00 & 0.00 & 0.00 & 33.99 & 0.10 & 0.04 & 0.24 \\
\hline credit spread & 0.00 & 0.00 & 3.07 & 0.00 & 0.00 & 0.00 & 0.00 & 0.00 & 96.93 & 0.00 \\
\hline \multicolumn{11}{|l|}{ Euro Area endogenous variables } \\
\hline output & 0.19 & 0.52 & 0.00 & 0.70 & 47.96 & 2.97 & 0.57 & 39.95 & 6.40 & 0.75 \\
\hline consumption & 0.00 & 0.00 & 0.00 & 0.01 & 35.61 & 0.30 & 0.01 & 63.67 & 0.39 & 0.02 \\
\hline investment & 0.00 & 0.00 & 0.00 & 0.12 & 31.67 & 7.28 & 0.15 & 44.06 & 16.44 & 0.26 \\
\hline labor & 0.03 & 0.10 & 0.00 & 72.32 & 10.57 & 0.87 & 6.66 & 7.41 & 1.54 & 0.49 \\
\hline wage inflation & 0.00 & 0.00 & 0.00 & 80.86 & 3.00 & 0.11 & 5.61 & 10.26 & 0.09 & 0.06 \\
\hline net worth & 0.00 & 0.00 & 0.00 & 0.05 & 0.01 & 30.20 & 0.04 & 0.01 & 69.69 & 0.00 \\
\hline interest rates & 0.01 & 0.02 & 0.03 & 4.12 & 3.84 & 36.36 & 4.13 & 3.84 & 45.90 & 1.75 \\
\hline inflation, foreign goods & 0.20 & 0.14 & 0.54 & 27.85 & 0.10 & 0.97 & 48.36 & 0.15 & 0.16 & 21.52 \\
\hline inflation, domestic goods & 0.00 & 0.02 & 0.01 & 60.14 & 0.39 & 0.42 & 36.41 & 1.39 & 0.11 & 1.10 \\
\hline credit spread & 0.00 & 0.00 & 0.00 & 0.00 & 0.00 & 51.16 & 0.00 & 0.00 & 48.84 & 0.00 \\
\hline \multicolumn{11}{|l|}{ forecast horizon $=4$ quarters } \\
\hline & \multicolumn{3}{|c|}{ U.S. shocks } & \multicolumn{3}{|c|}{ Euro Area shocks } & \multicolumn{4}{|c|}{ Common shocks } \\
\hline U.S. endogenous variables & $\begin{array}{c}\text { Productivity } \\
\text { \& cost-push } \\
\text { shocks }\end{array}$ & $\begin{array}{c}\text { Demand } \\
\text { shocks }\end{array}$ & $\begin{array}{c}\text { Financial } \\
\text { shocks }\end{array}$ & $\begin{array}{c}\text { Productivity } \\
\text { \& cost-push } \\
\text { shocks }\end{array}$ & $\begin{array}{c}\text { Demand } \\
\text { shocks }\end{array}$ & $\begin{array}{l}\text { Financial } \\
\text { shocks }\end{array}$ & $\begin{array}{c}\text { Productivity } \\
\text { \& cost-push } \\
\text { shocks }\end{array}$ & $\begin{array}{l}\text { Demand } \\
\text { shocks }\end{array}$ & $\begin{array}{c}\text { Financial } \\
\text { shocks }\end{array}$ & $\begin{array}{l}\text { Exchange } \\
\text { rate shocks }\end{array}$ \\
\hline output & 0.31 & 60.04 & 0.94 & 1.06 & 0.11 & 0.02 & 2.12 & 20.83 & 14.36 & 0.21 \\
\hline consumption & 0.26 & 50.86 & 0.76 & 0.13 & 0.01 & 0.13 & 0.52 & 43.14 & 3.81 & 0.38 \\
\hline investment & 0.48 & 32.82 & 0.57 & 0.02 & 0.00 & 0.00 & 0.29 & 23.90 & 41.42 & 0.49 \\
\hline labor & 48.29 & 27.80 & 0.48 & 0.28 & 0.05 & 0.01 & 6.61 & 8.74 & 7.13 & 0.62 \\
\hline wage inflation & 47.54 & 6.54 & 1.15 & 0.30 & 0.02 & 0.34 & 31.24 & 8.82 & 1.20 & 2.84 \\
\hline net worth & 0.22 & 0.01 & 0.31 & 0.00 & 0.00 & 0.00 & 0.13 & 0.00 & 99.26 & 0.06 \\
\hline interest rates & 14.95 & 1.68 & 30.57 & 0.15 & 0.01 & 0.13 & 7.99 & 0.88 & 37.61 & 6.03 \\
\hline inflation, foreign goods & 41.28 & 0.17 & 0.59 & 2.17 & 0.11 & 0.98 & 30.43 & 0.07 & 0.27 & 23.92 \\
\hline inflation, domestic goods & 64.47 & 0.44 & 0.16 & 0.00 & 0.00 & 0.02 & 32.55 & 0.56 & 0.29 & 1.50 \\
\hline credit spread & 0.01 & 0.00 & 3.02 & 0.00 & 0.00 & 0.00 & 0.00 & 0.00 & 96.97 & 0.00 \\
\hline \multicolumn{11}{|l|}{ Euro Area endogenous variables } \\
\hline output & 0.22 & 0.44 & 0.00 & 0.92 & 38.35 & 5.48 & 0.81 & 39.46 & 13.23 & 1.08 \\
\hline consumption & 0.00 & 0.00 & 0.00 & 0.02 & 32.78 & 0.79 & 0.01 & 65.32 & 0.99 & 0.08 \\
\hline investment & 0.00 & 0.01 & 0.00 & 0.13 & 20.17 & 11.71 & 0.14 & 38.73 & 28.76 & 0.34 \\
\hline labor & 0.04 & 0.10 & 0.00 & 70.47 & 9.23 & 1.71 & 6.57 & 7.87 & 3.35 & 0.67 \\
\hline wage inflation & 0.01 & 0.01 & 0.02 & 75.82 & 2.86 & 0.26 & 8.00 & 11.11 & 0.17 & 1.73 \\
\hline net worth & 0.00 & 0.00 & 0.00 & 0.08 & 0.01 & 30.06 & 0.08 & 0.03 & 69.72 & 0.03 \\
\hline interest rates & 0.02 & 0.04 & 0.07 & 6.47 & 3.61 & 29.67 & 7.55 & 8.12 & 38.06 & 6.39 \\
\hline inflation, foreign goods & 0.20 & 0.23 & 0.48 & 25.85 & 0.21 & 1.54 & 44.89 & 0.37 & 0.20 & 26.03 \\
\hline inflation, domestic goods & 0.01 & 0.08 & 0.03 & 55.65 & 1.43 & 1.79 & 31.22 & 4.93 & 0.48 & 4.38 \\
\hline credit spread & 0.00 & 0.00 & 0.00 & 0.00 & 0.00 & 51.00 & 0.00 & 0.00 & 48.99 & 0.00 \\
\hline
\end{tabular}

Notes: Forecast error variance decompositions are obtained by using the posterior mean values of the model parameters. 
Table 4 (continued). Forecast error variance decompositions, model with common shocks.

\begin{tabular}{|c|c|c|c|c|c|c|c|c|c|c|}
\hline \multicolumn{11}{|c|}{ recast hornzon $=10$ quarters } \\
\hline \multirow{2}{*}{$\begin{array}{l}\text { U.S. endogenous variables } \\
\text { output }\end{array}$} & $\begin{array}{l}\text { Productivity } \\
\text { \& cost-push } \\
\text { shocks }\end{array}$ & $\begin{array}{l}\text { Demand } \\
\text { shocks }\end{array}$ & $\begin{array}{l}\text { Financial } \\
\text { shocks }\end{array}$ & $\begin{array}{l}\text { Productivity } \\
\text { \& cost-push } \\
\text { shocks }\end{array}$ & $\begin{array}{l}\text { Demand } \\
\text { shocks }\end{array}$ & $\begin{array}{l}\text { Financial } \\
\text { shocks }\end{array}$ & $\begin{array}{l}\text { Productivity } \\
\text { \& cost-push } \\
\text { shocks }\end{array}$ & $\begin{array}{l}\text { Demand } \\
\text { shocks }\end{array}$ & $\begin{array}{l}\text { Financial } \\
\text { shocks }\end{array}$ & $\begin{array}{l}\text { Exchange } \\
\text { rate shocks }\end{array}$ \\
\hline & 0.43 & 57.45 & 1.04 & 1.08 & 0.11 & 0.03 & 2.29 & 20.31 & 17.06 & 0.20 \\
\hline consumption & 0.28 & 49.88 & 0.74 & 0.22 & 0.02 & 0.21 & 0.63 & 42.24 & 5.33 & 0.44 \\
\hline investment & 0.70 & 29.67 & 0.78 & 0.02 & 0.00 & 0.00 & 0.34 & 21.35 & 46.65 & 0.47 \\
\hline labor & 47.07 & 27.54 & 0.55 & 0.34 & 0.05 & 0.01 & 6.54 & 8.93 & 8.38 & 0.60 \\
\hline wage inflation & 46.85 & 6.30 & 1.14 & 0.38 & 0.03 & 0.49 & 29.56 & 8.43 & 2.69 & 4.12 \\
\hline net worth & 0.23 & 0.01 & 0.31 & 0.00 & 0.00 & 0.00 & 0.13 & 0.01 & 99.23 & 0.07 \\
\hline interest rates & 14.90 & 2.26 & 28.30 & 0.16 & 0.02 & 0.15 & 7.88 & 1.39 & 37.84 & 7.10 \\
\hline inflation, foreign goods & 42.75 & 0.20 & 0.60 & 2.08 & 0.12 & 1.09 & 29.63 & 0.08 & 0.26 & 23.19 \\
\hline inflation, domestic goods & 62.81 & 0.81 & 0.28 & 0.00 & 0.01 & 0.04 & 31.34 & 1.00 & 0.71 & 2.99 \\
\hline spreads & 0.02 & 0.01 & 2.93 & 0.00 & 0.00 & 0.00 & 0.01 & 0.01 & 97.02 & 0.01 \\
\hline \multicolumn{11}{|l|}{ Euro Area endogenous variables } \\
\hline output & 0.22 & 0.42 & 0.00 & 0.89 & 35.49 & 6.89 & 0.77 & 37.04 & 17.26 & 1.01 \\
\hline consumption & 0.00 & 0.01 & 0.00 & 0.08 & 32.31 & 1.31 & 0.10 & 64.56 & 1.51 & 0.11 \\
\hline investment & 0.00 & 0.01 & 0.00 & 0.32 & 17.09 & 14.13 & 0.42 & 33.13 & 34.58 & 0.31 \\
\hline labor & 0.05 & 0.10 & 0.00 & 69.31 & 9.04 & 2.12 & 6.53 & 7.91 & 4.27 & 0.66 \\
\hline wage inflation & 0.01 & 0.02 & 0.02 & 73.82 & 2.89 & 0.96 & 7.91 & 10.96 & 0.89 & 2.52 \\
\hline net worth & 0.00 & 0.00 & 0.00 & 0.08 & 0.01 & 30.02 & 0.08 & 0.04 & 69.72 & 0.04 \\
\hline interest rates & 0.03 & 0.09 & 0.06 & 6.42 & 3.58 & 29.21 & 7.16 & 9.31 & 36.65 & 7.50 \\
\hline inflation, foreign goods & 0.20 & 0.26 & 0.43 & 27.19 & 0.26 & 1.84 & 46.78 & 0.47 & 0.18 & 22.40 \\
\hline inflation, domestic goods & 0.03 & 0.18 & 0.06 & 49.36 & 2.51 & 4.19 & 26.65 & 7.94 & 1.10 & 7.99 \\
\hline spreads & 0.00 & 0.00 & 0.00 & 0.00 & 0.00 & 50.57 & 0.00 & 0.00 & 49.42 & 0.00 \\
\hline \multicolumn{11}{|l|}{ forecast horizon $=100$ quarters } \\
\hline & \multicolumn{3}{|c|}{ U.S. shocks } & \multicolumn{3}{|c|}{ Euro Area shocks } & \multicolumn{4}{|c|}{ Common shocks } \\
\hline U.S. endogenous variables & $\begin{array}{l}\text { Productivity } \\
\text { \& cost-push } \\
\text { shocks }\end{array}$ & $\begin{array}{l}\text { Demand } \\
\text { shocks }\end{array}$ & $\begin{array}{l}\text { Financial } \\
\text { shocks }\end{array}$ & $\begin{array}{l}\text { Productivity } \\
\text { \& cost-push } \\
\text { shocks }\end{array}$ & $\begin{array}{l}\text { Demand } \\
\text { shocks }\end{array}$ & $\begin{array}{l}\text { Financial } \\
\text { shocks }\end{array}$ & $\begin{array}{l}\text { Productivity } \\
\text { \& cost-push } \\
\text { shocks }\end{array}$ & $\begin{array}{l}\text { Demand } \\
\text { shocks }\end{array}$ & $\begin{array}{l}\text { Financial } \\
\text { shocks }\end{array}$ & $\begin{array}{l}\text { Exchange } \\
\text { rate shocks }\end{array}$ \\
\hline output & 0.49 & 55.43 & 1.09 & 1.09 & 0.10 & 0.03 & 2.36 & 20.26 & 18.96 & 0.20 \\
\hline consumption & 0.34 & 49.12 & 0.77 & 0.31 & 0.02 & 0.31 & 0.70 & 41.64 & 6.37 & 0.42 \\
\hline investment & 0.77 & 27.50 & 0.85 & 0.02 & 0.00 & 0.01 & 0.35 & 20.68 & 49.30 & 0.53 \\
\hline labor & 45.96 & 27.18 & 0.57 & 0.37 & 0.05 & 0.01 & 6.45 & 9.14 & 9.67 & 0.61 \\
\hline wage inflation & 41.33 & 5.80 & 1.04 & 0.95 & 0.07 & 1.21 & 26.78 & 7.98 & 10.50 & 4.33 \\
\hline net worth & 0.24 & 0.01 & 0.32 & 0.00 & 0.00 & 0.00 & 0.13 & 0.01 & 99.21 & 0.07 \\
\hline interest rates & 14.22 & 2.48 & 26.33 & 0.32 & 0.03 & 0.32 & 7.61 & 1.68 & 40.37 & 6.65 \\
\hline inflation, foreign goods & 43.34 & 0.22 & 0.58 & 2.06 & 0.12 & 1.19 & 28.94 & 0.08 & 0.28 & 23.19 \\
\hline inflation, domestic goods & 58.31 & 1.03 & 0.32 & 0.49 & 0.04 & 0.64 & 29.74 & 1.35 & 4.53 & 3.54 \\
\hline spreads & 0.02 & 0.04 & 2.83 & 0.00 & 0.00 & 0.00 & 0.01 & 0.05 & 97.03 & 0.02 \\
\hline \multicolumn{11}{|l|}{ Euro Area endogenous variables } \\
\hline output & 0.22 & 0.40 & 0.00 & 0.87 & 33.15 & 7.78 & 0.75 & 36.16 & 19.66 & 1.00 \\
\hline consumption & 0.01 & 0.02 & 0.00 & 0.24 & 31.71 & 1.57 & 0.33 & 64.01 & 1.98 & 0.13 \\
\hline investment & 0.01 & 0.02 & 0.00 & 0.37 & 15.03 & 15.20 & 0.49 & 31.41 & 37.15 & 0.33 \\
\hline labor & 0.05 & 0.10 & 0.00 & 67.92 & 8.93 & 2.45 & 6.44 & 8.21 & 5.20 & 0.68 \\
\hline wage inflation & 0.24 & 0.42 & 0.05 & 61.38 & 2.80 & 3.05 & 11.97 & 9.52 & 7.41 & 3.15 \\
\hline net worth & 0.00 & 0.00 & 0.00 & 0.12 & 0.02 & 29.85 & 0.13 & 0.04 & 69.79 & 0.05 \\
\hline interest rates & 0.27 & 0.49 & 0.08 & 9.47 & 3.49 & 26.24 & 12.07 & 8.63 & 32.92 & 6.35 \\
\hline inflation, foreign goods & 0.24 & 0.28 & 0.39 & 27.81 & 0.31 & 2.18 & 47.18 & 0.54 & 0.54 & 20.53 \\
\hline inflation, domestic goods & 0.66 & 1.29 & 0.14 & 31.43 & 3.07 & 7.43 & 26.97 & 6.93 & 14.02 & 8.07 \\
\hline spreads & 0.00 & 0.00 & 0.00 & 0.00 & 0.01 & 49.92 & 0.00 & 0.03 & 50.03 & 0.00 \\
\hline
\end{tabular}

Notes: Forecast error variance decompositions are obtained by using the posterior mean values of the model parameters. 
Table 5. Forecast error variance decompositions, comparison across models

\begin{tabular}{|c|c|c|c|c|c|c|c|c|c|c|}
\hline \multicolumn{11}{|l|}{ Horizon $=1$ quarter } \\
\hline & \multicolumn{2}{|c|}{ Baseline model } & \multicolumn{2}{|c|}{$\begin{array}{l}\text { Model with shock } \\
\text { correlation }\end{array}$} & \multicolumn{3}{|c|}{ Model with common shocks } & \multicolumn{3}{|c|}{$\begin{array}{l}\text { Model with common shocks and } \\
\text { shock correlation }\end{array}$} \\
\hline & & Euro & & Euro & & Euro & & & Euro & \\
\hline & $\begin{array}{c}\text { U.S. } \\
\text { shocks }\end{array}$ & $\begin{array}{c}\text { Area } \\
\text { shocks }\end{array}$ & $\begin{array}{c}\text { U.S. } \\
\text { shocks }\end{array}$ & $\begin{array}{c}\text { Area } \\
\text { shocks }\end{array}$ & $\begin{array}{c}\text { U.S. } \\
\text { shocks }\end{array}$ & $\begin{array}{c}\text { Area } \\
\text { shocks }\end{array}$ & $\begin{array}{c}\text { Common } \\
\text { shocks }\end{array}$ & $\begin{array}{c}\text { U.S. } \\
\text { shocks }\end{array}$ & $\begin{array}{c}\text { Area } \\
\text { shocks }\end{array}$ & $\begin{array}{c}\text { Common } \\
\text { shocks }\end{array}$ \\
\hline \multicolumn{11}{|l|}{ U.S. endogenous variables } \\
\hline output & 97.39 & 2.52 & 73.13 & 26.86 & 69.96 & 0.86 & 29.03 & 66.19 & 13.54 & 20.24 \\
\hline consumption & 99.25 & 0.58 & 70.05 & 29.81 & 54.81 & 0.08 & 44.99 & 57.13 & 16.33 & 26.41 \\
\hline investment & 99.57 & 0.16 & 64.54 & 35.26 & 47.24 & 0.01 & 52.36 & 49.14 & 9.57 & 40.89 \\
\hline labor & 98.91 & 0.62 & 81.15 & 18.57 & 80.68 & 0.24 & 18.60 & 74.54 & 10.76 & 14.34 \\
\hline wage inflation & 98.32 & 1.53 & 70.00 & 29.91 & 54.82 & 0.40 & 44.54 & 48.34 & 18.33 & 33.17 \\
\hline net worth & 99.94 & 0.02 & 47.06 & 52.92 & 0.35 & 0.00 & 99.64 & 1.93 & 3.76 & 94.28 \\
\hline interest rates & 92.59 & 2.51 & 63.79 & 33.83 & 47.65 & 0.13 & 50.08 & 52.44 & 16.77 & 28.35 \\
\hline inflation, foreign goods & 36.19 & 27.43 & 44.93 & 17.97 & 43.86 & 2.75 & 30.70 & 46.14 & 4.63 & 22.20 \\
\hline inflation, domestic goods & 99.87 & 0.01 & 79.53 & 20.36 & 65.63 & 0.00 & 34.13 & 61.38 & 9.64 & 28.77 \\
\hline credit spread & 100.00 & 0.00 & 38.69 & 61.31 & 3.07 & 0.00 & 96.93 & 37.00 & 60.17 & 2.83 \\
\hline \multicolumn{11}{|l|}{ Euro Area endogenous variables } \\
\hline output & 0.84 & 98.60 & 34.54 & 65.28 & 0.71 & 51.63 & 46.92 & 21.49 & 48.52 & 29.61 \\
\hline consumption & 0.26 & 99.72 & 38.98 & 61.01 & 0.00 & 35.91 & 64.07 & 23.19 & 40.25 & 36.55 \\
\hline investment & 0.58 & 99.25 & 31.33 & 68.57 & 0.01 & 39.08 & 60.66 & 8.13 & 44.46 & 47.21 \\
\hline labor & 0.26 & 99.44 & 15.28 & 84.60 & 0.14 & 83.75 & 15.61 & 9.76 & 77.20 & 12.76 \\
\hline wage inflation & 0.16 & 99.82 & 6.68 & 93.31 & 0.01 & 83.97 & 15.96 & 6.13 & 82.81 & 11.02 \\
\hline net worth & 0.00 & 100.00 & 39.03 & 60.97 & 0.00 & 30.26 & 69.74 & 2.58 & 32.86 & 64.57 \\
\hline interest rates & 1.06 & 98.24 & 35.38 & 64.41 & 0.06 & 44.32 & 53.88 & 18.13 & 49.89 & 31.17 \\
\hline inflation, foreign goods & 19.81 & 71.06 & 56.04 & 42.41 & 0.89 & 28.93 & 48.67 & 18.32 & 8.95 & 63.42 \\
\hline inflation, domestic goods & 0.55 & 99.20 & 22.36 & 77.36 & 0.03 & 60.96 & 37.91 & 10.76 & 56.56 & 31.67 \\
\hline credit spread & 0.00 & 100.00 & 32.85 & 67.15 & 0.00 & 51.16 & 48.84 & 31.73 & 66.78 & 1.49 \\
\hline \multicolumn{11}{|l|}{$\underline{\text { Horizon }=10 \text { quarters }}$} \\
\hline \multicolumn{11}{|l|}{ U.S. endogenous variables } \\
\hline output & 96.46 & 3.43 & 68.51 & 31.47 & 58.93 & 1.21 & 39.66 & 58.63 & 12.57 & 28.76 \\
\hline consumption & 97.60 & 2.07 & 68.79 & 30.87 & 50.91 & 0.45 & 48.21 & 55.26 & 15.80 & 28.50 \\
\hline investment & 99.57 & 0.17 & 58.64 & 41.16 & 31.16 & 0.02 & 68.35 & 34.56 & 7.95 & 56.99 \\
\hline labor & 98.48 & 1.04 & 77.79 & 21.95 & 75.16 & 0.39 & 23.85 & 70.59 & 10.33 & 18.66 \\
\hline wage inflation & 94.70 & 2.80 & 70.32 & 27.80 & 54.30 & 0.90 & 40.68 & 51.65 & 15.86 & 29.30 \\
\hline net worth & 99.87 & 0.05 & 47.11 & 52.85 & 0.56 & 0.00 & 99.36 & 2.15 & 3.79 & 93.97 \\
\hline interest rates & 90.48 & 3.04 & 62.94 & 32.74 & 45.46 & 0.33 & 47.10 & 51.69 & 14.35 & 27.57 \\
\hline inflation, foreign goods & 38.26 & 27.87 & 45.72 & 18.17 & 43.55 & 3.30 & 29.97 & 47.75 & 4.93 & 20.10 \\
\hline inflation, domestic goods & 98.34 & 0.18 & 78.12 & 20.58 & 63.91 & 0.05 & 33.04 & 61.94 & 9.48 & 26.12 \\
\hline credit spread & 99.99 & 0.00 & 39.08 & 60.92 & 2.96 & 0.00 & 97.04 & 36.08 & 58.65 & 5.27 \\
\hline \multicolumn{11}{|l|}{ Euro Area endogenous variables } \\
\hline output & 0.97 & 98.41 & 35.57 & 64.22 & 0.64 & 43.27 & 55.07 & 17.99 & 43.66 & 37.81 \\
\hline consumption & 1.84 & 98.08 & 38.99 & 60.93 & 0.02 & 33.70 & 66.17 & 22.78 & 40.30 & 36.82 \\
\hline investment & 1.17 & 98.61 & 34.33 & 65.52 & 0.02 & 31.53 & 68.13 & 5.94 & 36.43 & 57.35 \\
\hline labor & 0.32 & 99.31 & 16.41 & 83.43 & 0.15 & 80.47 & 18.71 & 9.17 & 75.11 & 15.33 \\
\hline wage inflation & 0.63 & 98.60 & 11.95 & 87.36 & 0.06 & 77.67 & 19.75 & 6.74 & 76.81 & 14.37 \\
\hline net worth & 0.04 & 99.95 & 39.04 & 60.96 & 0.00 & 30.12 & 69.83 & 2.68 & 32.68 & 64.61 \\
\hline interest rates & 7.78 & 89.45 & 38.54 & 59.72 & 0.18 & 39.21 & 53.12 & 15.74 & 43.46 & 35.50 \\
\hline inflation, foreign goods & 26.75 & 64.68 & 55.10 & 41.94 & 0.89 & 29.28 & 47.43 & 17.11 & 9.37 & 61.13 \\
\hline inflation, domestic goods & 5.90 & 92.07 & 28.46 & 68.91 & 0.27 & 56.06 & 35.69 & 10.99 & 53.93 & 27.32 \\
\hline credit spread & 0.00 & 100.00 & 33.01 & 66.99 & 0.00 & 50.57 & 49.43 & 31.25 & 66.24 & 2.51 \\
\hline
\end{tabular}

Notes: Forecast error variance decompositions are obtained by using the posterior mean values of the model parameters. 
Figure 1. Cross-country correlation of macroeconomic variables

\section{GDP growth rate}

\begin{tabular}{l|ccccccccr} 
& U.S. & U.K & Japan & Italy & Germany & France & Canada & EA & OECD \\
\hline U.S. & 1 & & & & & & & & \\
U.K & $0.6585^{*}$ & 1 & & & & & & & \\
Japan & $0.4733^{*}$ & $0.3511^{*}$ & 1 & & & & & & \\
Italy & $0.4273^{*}$ & 0.3073 & $0.6854^{*}$ & 1 & & & & & \\
Germany & 0.2386 & 0.1221 & $0.7349^{*}$ & $0.7487^{*}$ & 1 & & & & \\
France & $0.5742^{*}$ & $0.4841^{*}$ & $0.4327^{*}$ & $0.5599^{*}$ & $0.5531^{*}$ & 1 & & & \\
Canada & $0.6518^{*}$ & $0.4857^{*}$ & $0.3537^{*}$ & 0.312 & 0.0954 & -0.0011 & 1 & & \\
EA & $0.5161^{*}$ & $0.6243^{*}$ & $0.4579^{*}$ & $0.7656^{*}$ & $0.6012^{*}$ & $0.6606^{*}$ & $0.5477^{*}$ & 1 & \\
OECD & $0.9187^{*}$ & $0.8979^{*}$ & $0.7614^{*}$ & $0.8751^{*}$ & $0.7935^{*}$ & $0.8922^{*}$ & $0.8620^{*}$ & $0.9099^{*}$ & 1
\end{tabular}

\section{$\underline{\text { Inflation rate }}$}

\begin{tabular}{l|ccccccc} 
& U.S. & U.K & Japan & Italy & Germany & France & Canada \\
\hline U.S. & 1 & & & & & & \\
U.K & $0.7986^{*}$ & 1 & & & & & \\
Japan & $0.7179^{*}$ & $0.7835^{*}$ & 1 & & & & \\
Italy & $0.7336^{*}$ & $0.8066^{*}$ & $0.7060^{*}$ & 1 & & & \\
Germany & $0.6758^{*}$ & $0.6753^{*}$ & $0.6881^{*}$ & $0.6637^{*}$ & 1 & & \\
France & $0.7663^{*}$ & $0.8053^{*}$ & $0.6634^{*}$ & $0.9607^{*}$ & $0.6589^{*}$ & 1 & \\
Canada & $0.8395^{*}$ & $0.8471^{*}$ & $0.6817^{*}$ & $0.8709^{*}$ & $0.5872^{*}$ & $0.8911^{*}$ & 1
\end{tabular}

\section{$\underline{\text { Unemployment rate }}$}

\begin{tabular}{l|ccccccccr} 
& U.S. & U.K & Japan & Italy & Germany & France & Canada & EA & OECD \\
\hline U.S. & 1 & & & & & & & & \\
U.K & $0.7191^{*}$ & 1 & & & & & & & \\
Japan & $0.6210^{*}$ & 0.388 & 1 & & & & & & \\
Italy & 0.1942 & 0.2468 & 0.152 & 1 & & & & & \\
Germany & 0.2206 & 0.0294 & 0.1747 & -0.068 & 1 & & & & \\
France & $0.4484^{*}$ & $0.6494^{*}$ & 0.2851 & $0.5699^{*}$ & 0.3242 & 1 & & & \\
Canada & $0.8979^{*}$ & $0.6946^{*}$ & $0.5428^{*}$ & 0.3151 & 0.3028 & $0.6420^{*}$ & 1 & & \\
EA & $0.5710^{*}$ & $0.6050^{*}$ & 0.2943 & $0.7358^{*}$ & 0.3955 & $0.8670^{*}$ & $0.7030^{*}$ & 1 & \\
OECD & $0.9181^{*}$ & $0.7383^{*}$ & $0.6738^{*}$ & 0.4312 & 0.3483 & $0.7064^{*}$ & $0.9260^{*}$ & $0.8039^{*}$ & 1
\end{tabular}

Notes: The cross-country correlation coefficients are computed by using the year-on-year growth rates of quarterly real gross domestic product (by expenditure in constant prices, index 2010=1), consumer price indices (excluding energy and food items, index 2010=100) and unemployment (harmonized unemployment, all persons). * indicates that Bonferroni-adjusted p-values are less than 0.01 . 
Figure 2. Impulse responses to U.S. shocks
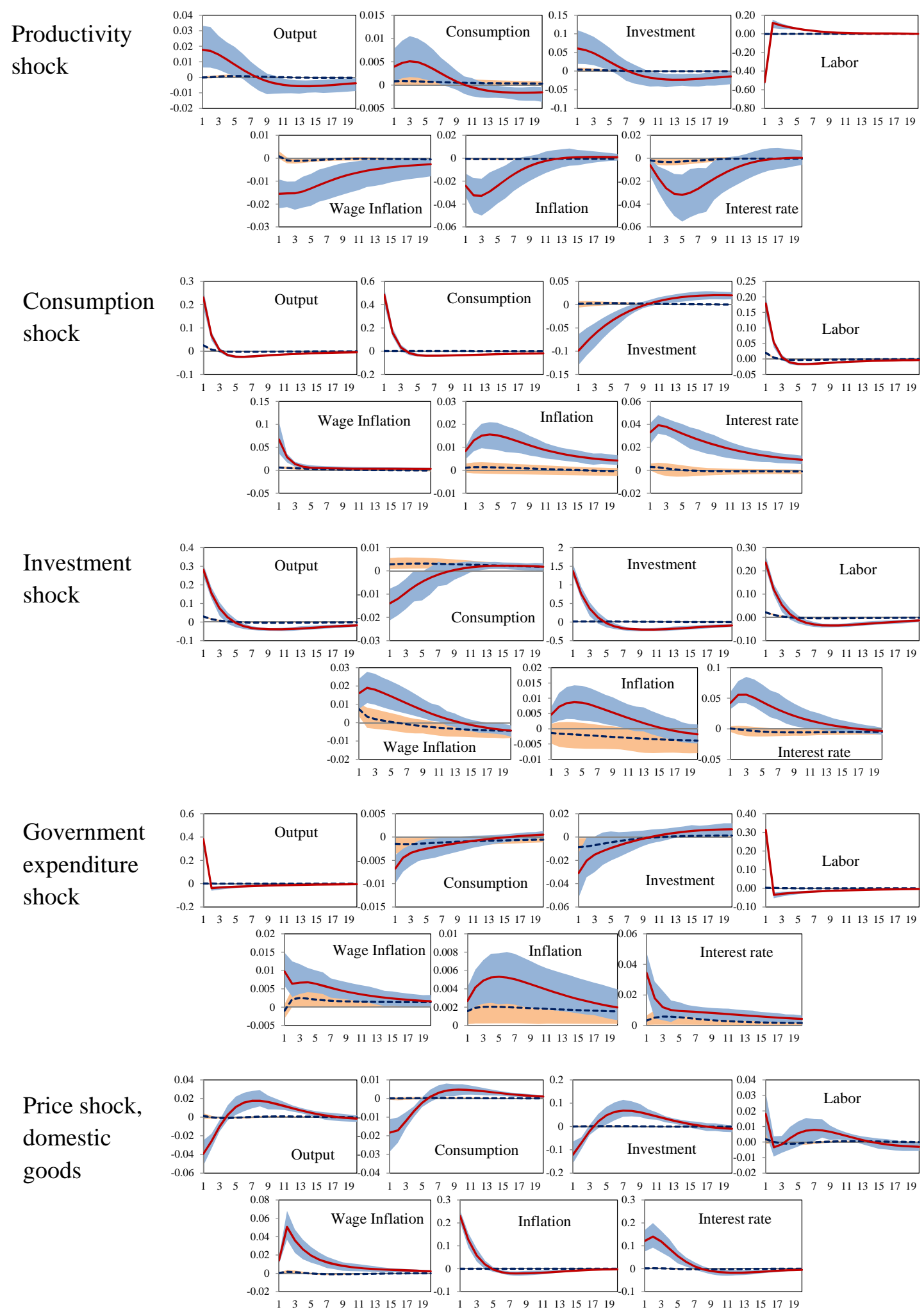

Notes: The figure displays the mean values and the 10 percent confidence band of the impulse responses (in standard deviations) generated by 1 standard deviation U.S. shocks. — U.S. responses, -ローーーー- Euro Area responses. 
Figure 2 (continued). Impulse responses to U.S. shocks
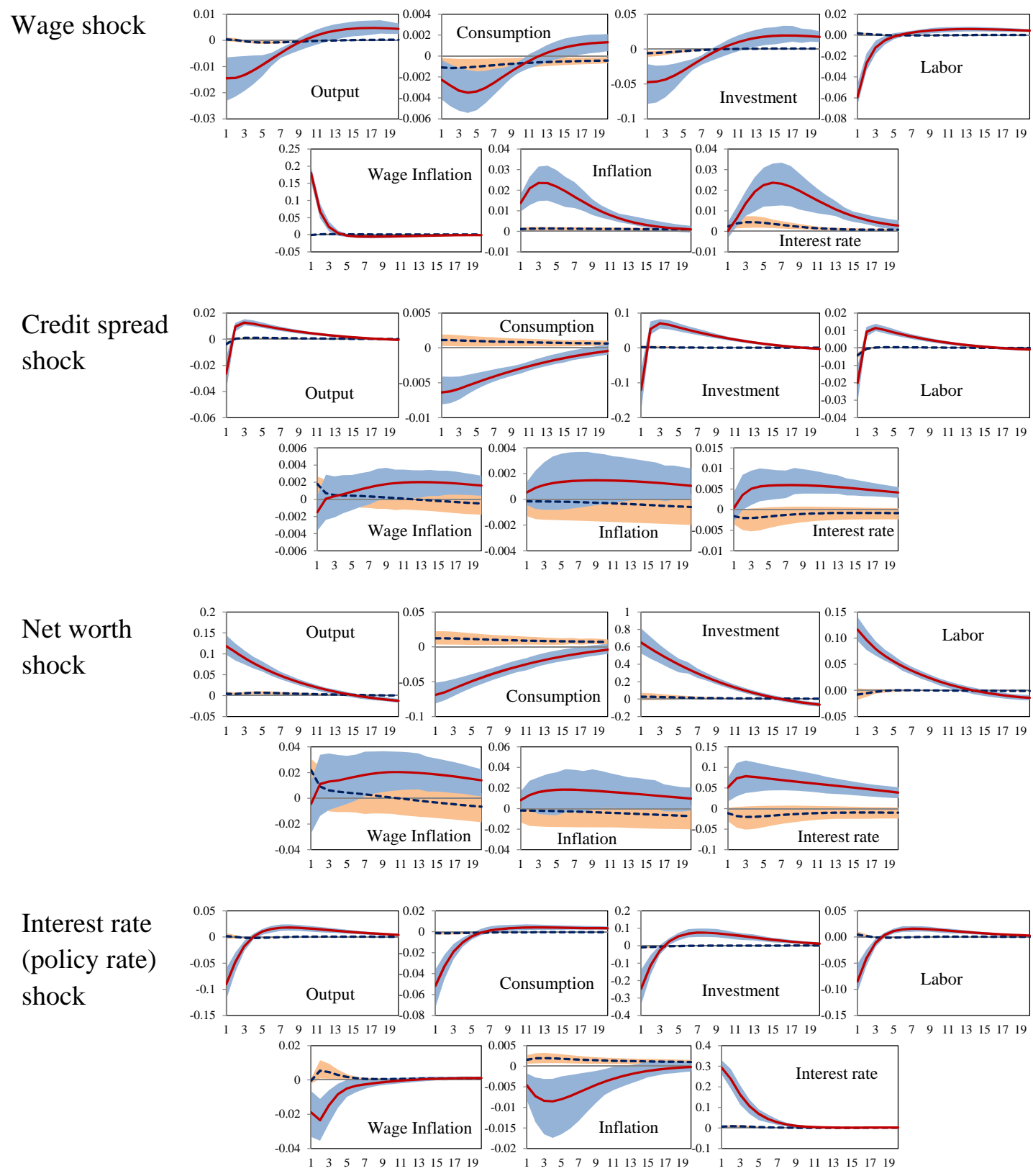

Notes: The figure displays the mean values and the 10 percent confidence band of the impulse responses (in standard deviations) generated by 1 standard deviation U.S. shocks. responses. 
Figure 3. Impulse responses to Euro Area shocks
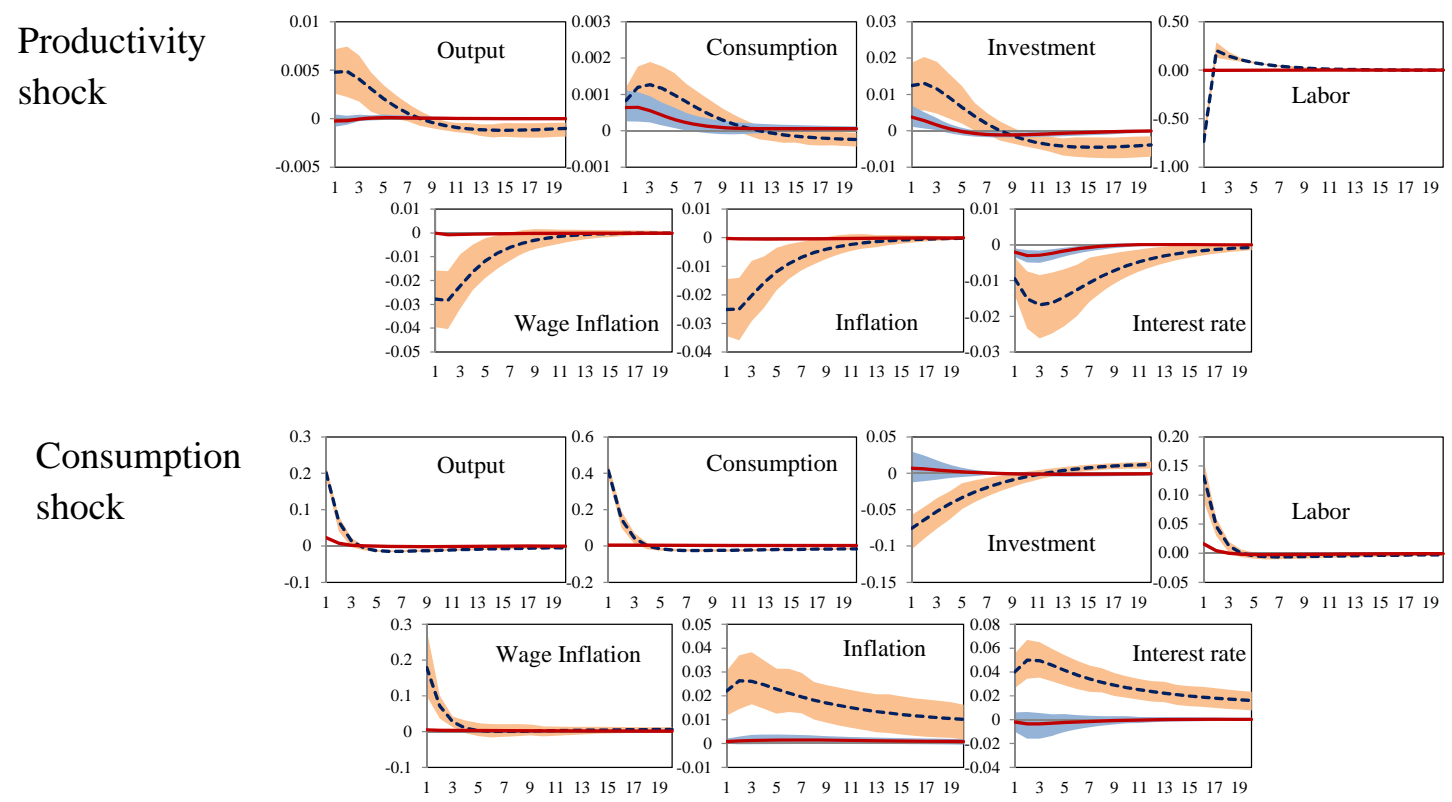

Investment shock
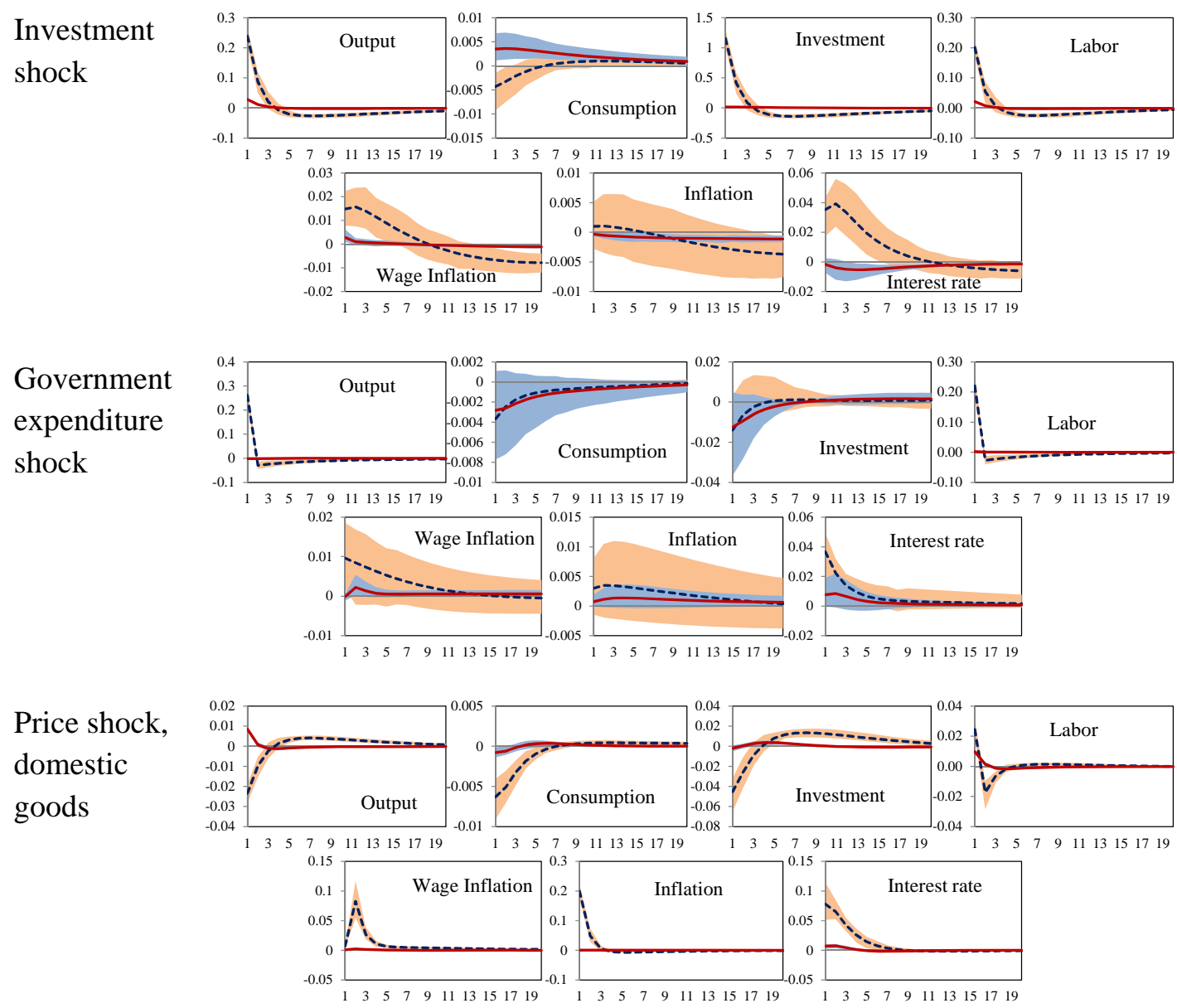

Notes: The figure displays the mean values and the 10 percent confidence band of the impulse responses (in standard deviations) generated by 1 standard deviation Euro Area shocks. — U.S. responses, -ーーーーー・ Euro Area responses. 
Figure 3 (continued). Impulse responses to Euro Area shocks
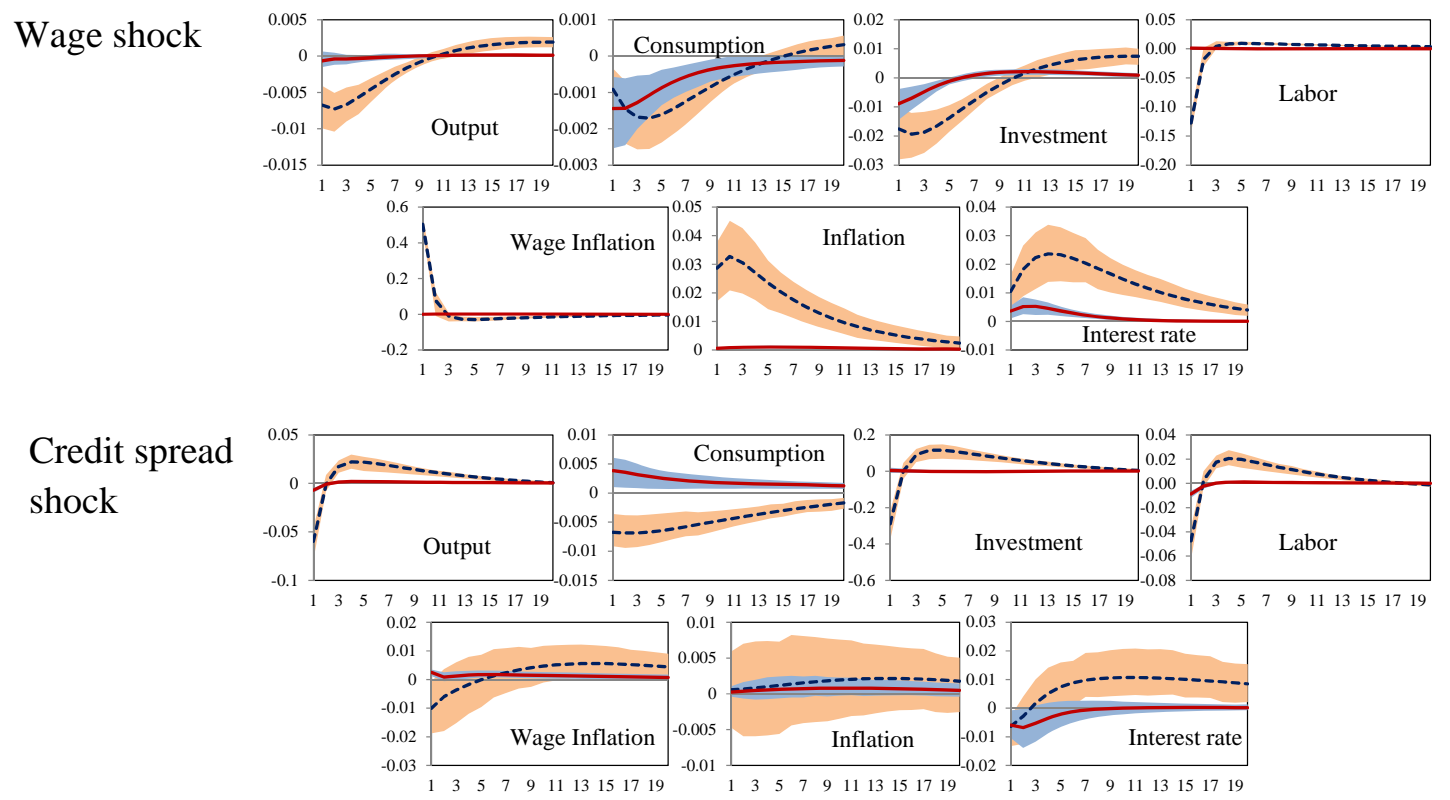

Net worth

shock
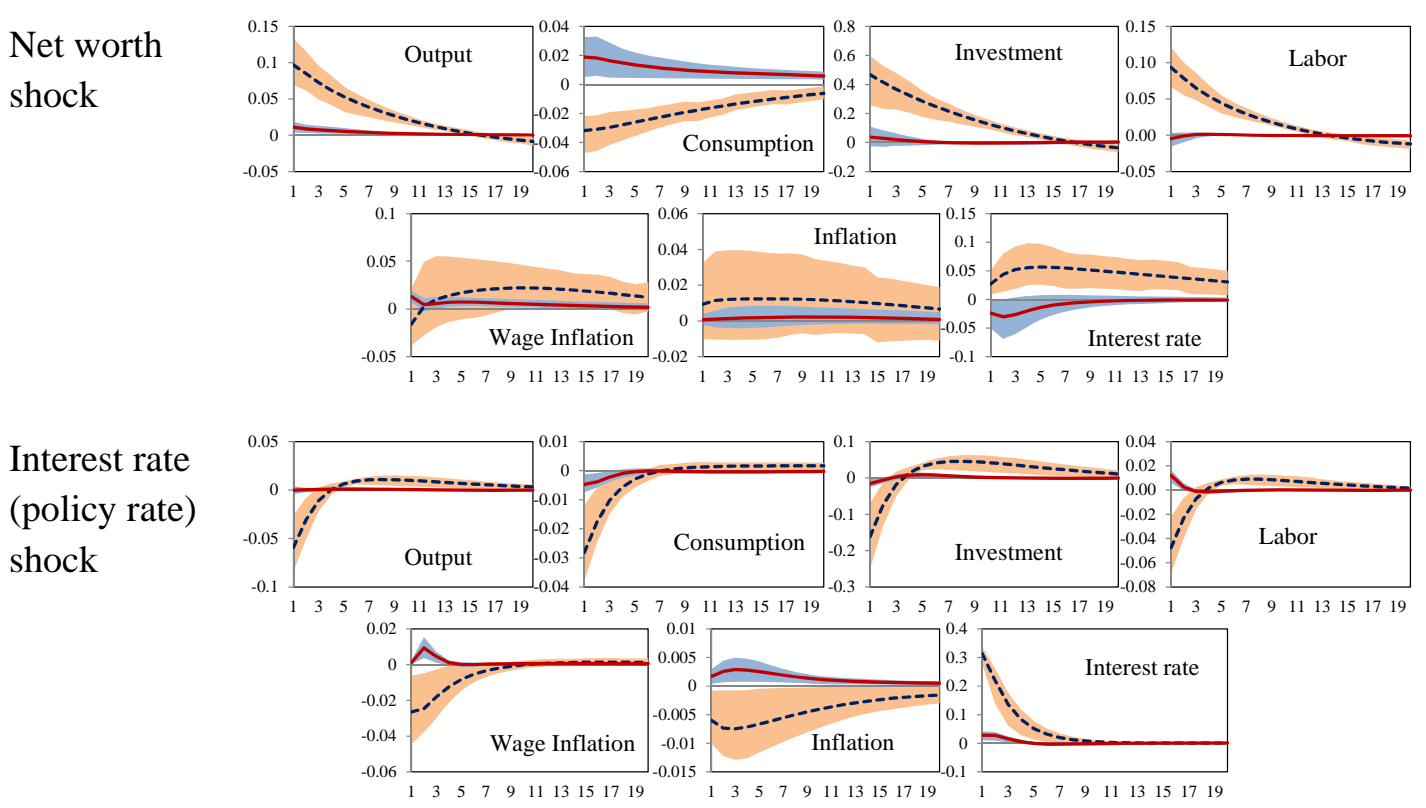

Notes: The figure displays the mean values and the 10 percent confidence band of the impulse responses (in standard deviations) generated by 1 standard deviation Euro Area shocks. Area responses.

U.S. responses, ローローロー・ Euro 
Figure 4. Historical decomposition of output

\section{U.S. Output}
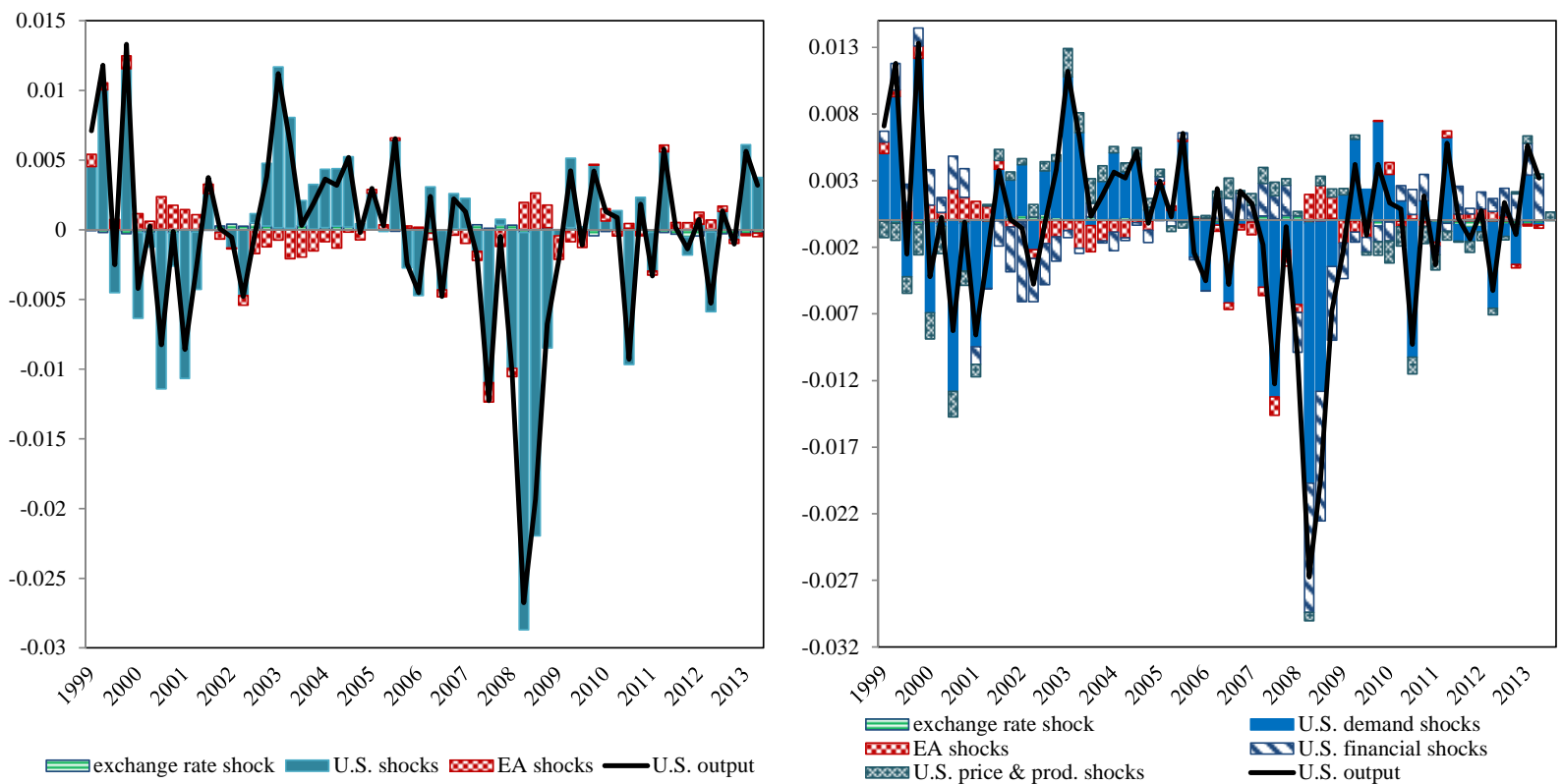

\section{Euro Area Output}
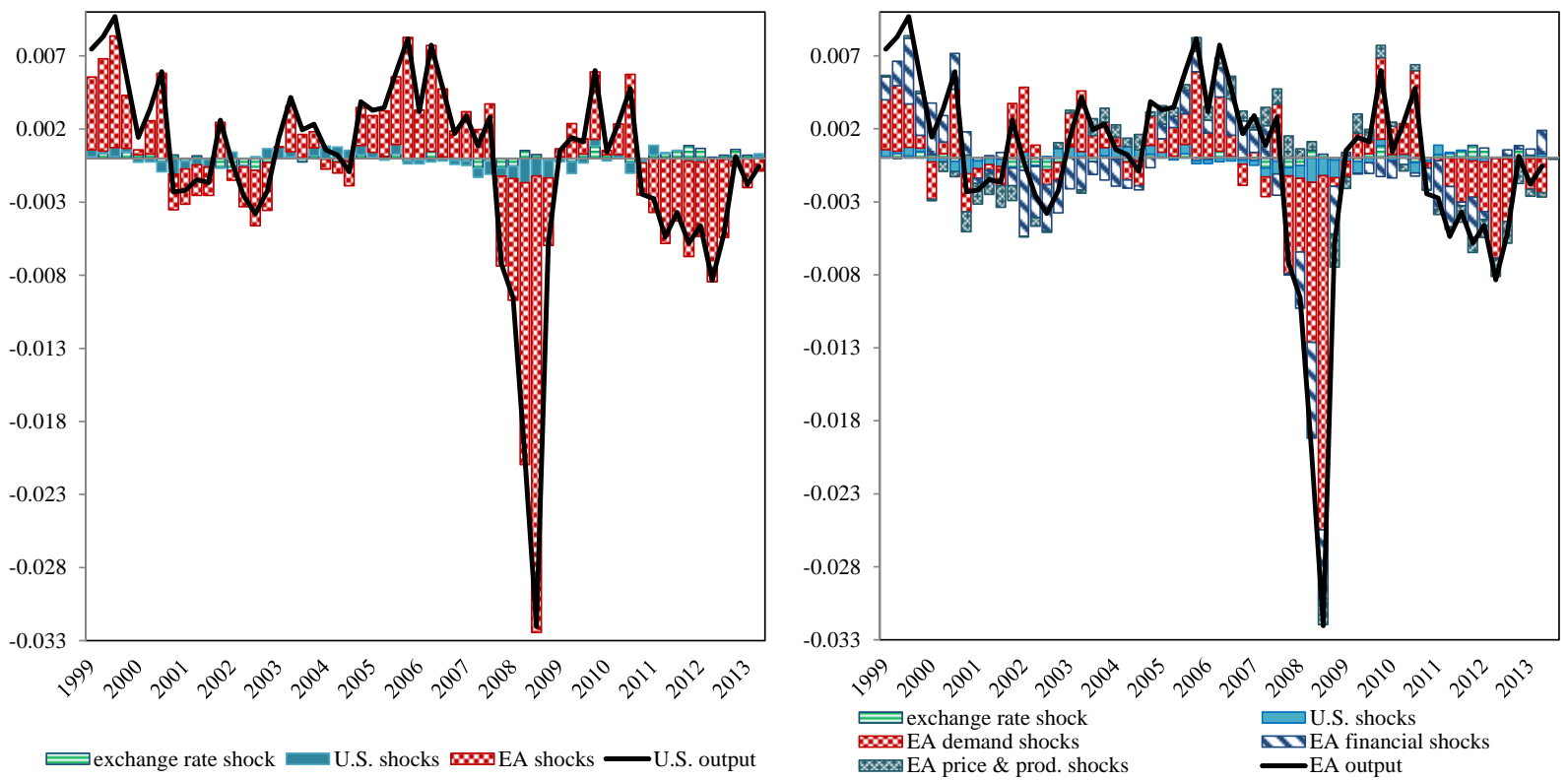

Notes: Demand shock includes, consumption, investment and government expenditure shocks. Financial shocks include credit spread, net worth and interest rate shocks. Price shocks include wage, domestic and foreign price shocks. 
Figure 5. Historical decomposition of U.S. output, model with common shocks
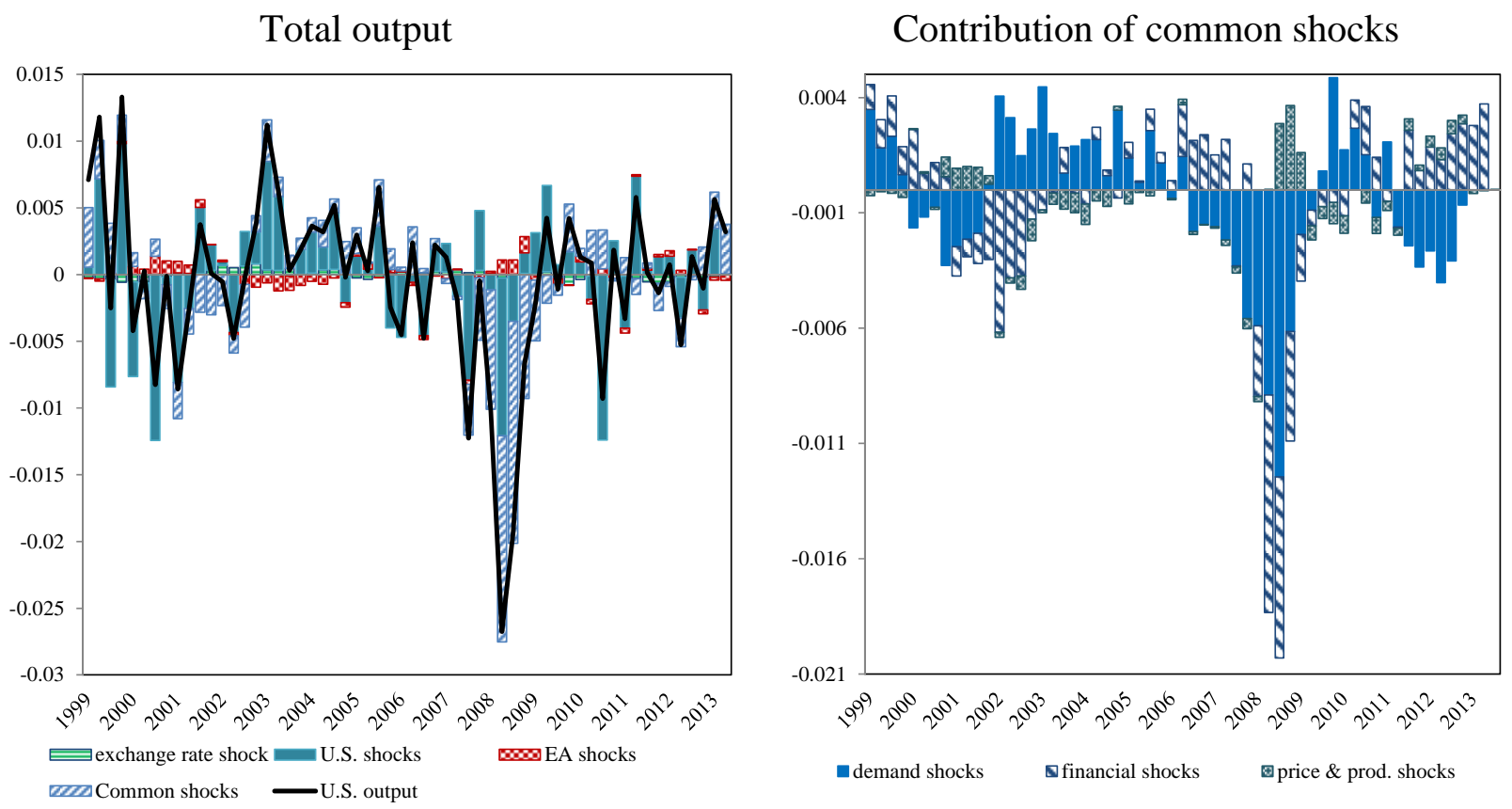

Contribution of common demand shocks

Contribution of common financial shocks
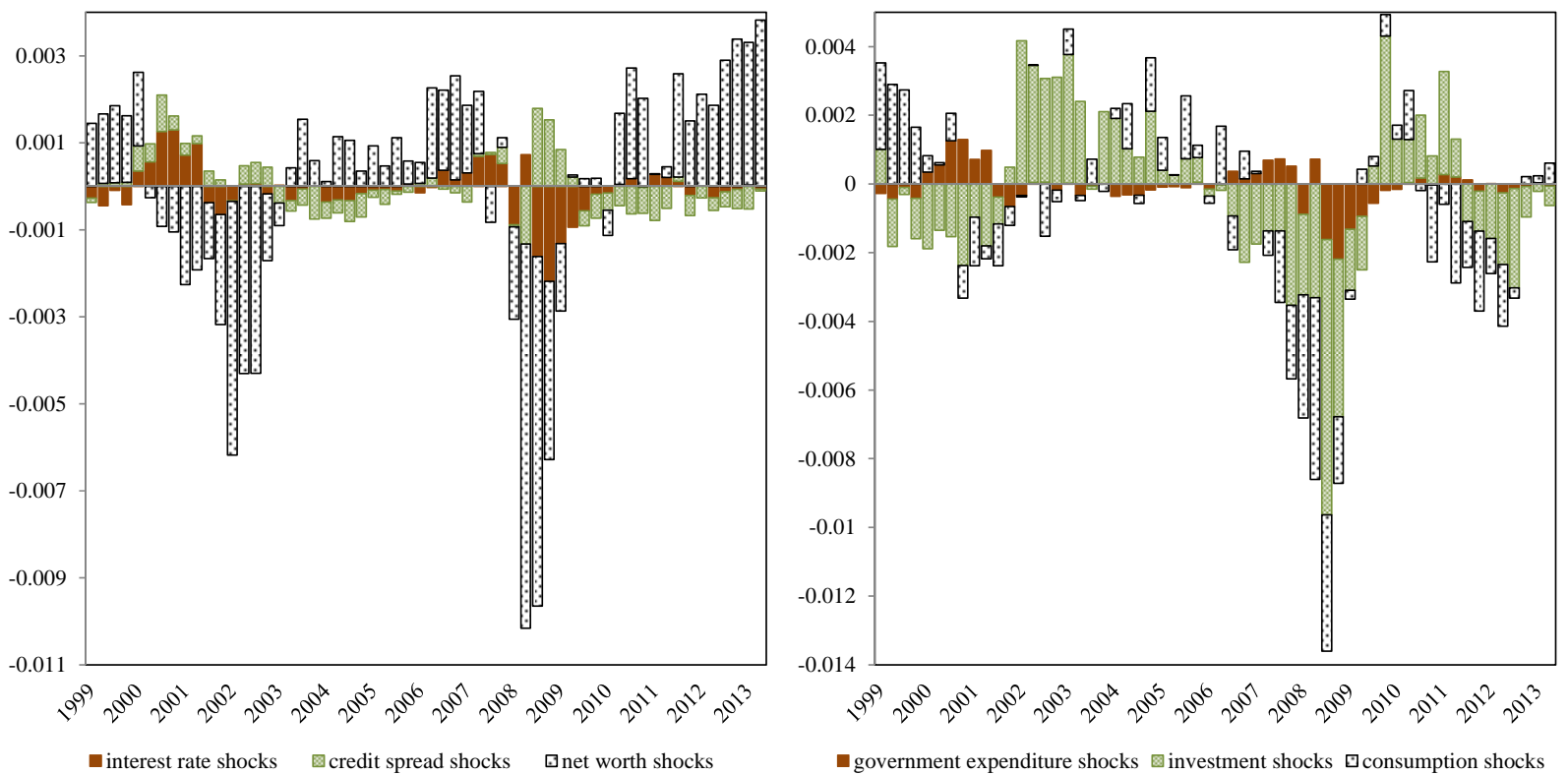

Notes: Demand shock includes, consumption, investment and government expenditure shocks. Financial shocks include credit spread, net worth and interest rate shocks. Price shocks include wage, domestic and foreign price shocks. 
Figure 6. Historical decomposition of Euro Area output, model with common shocks
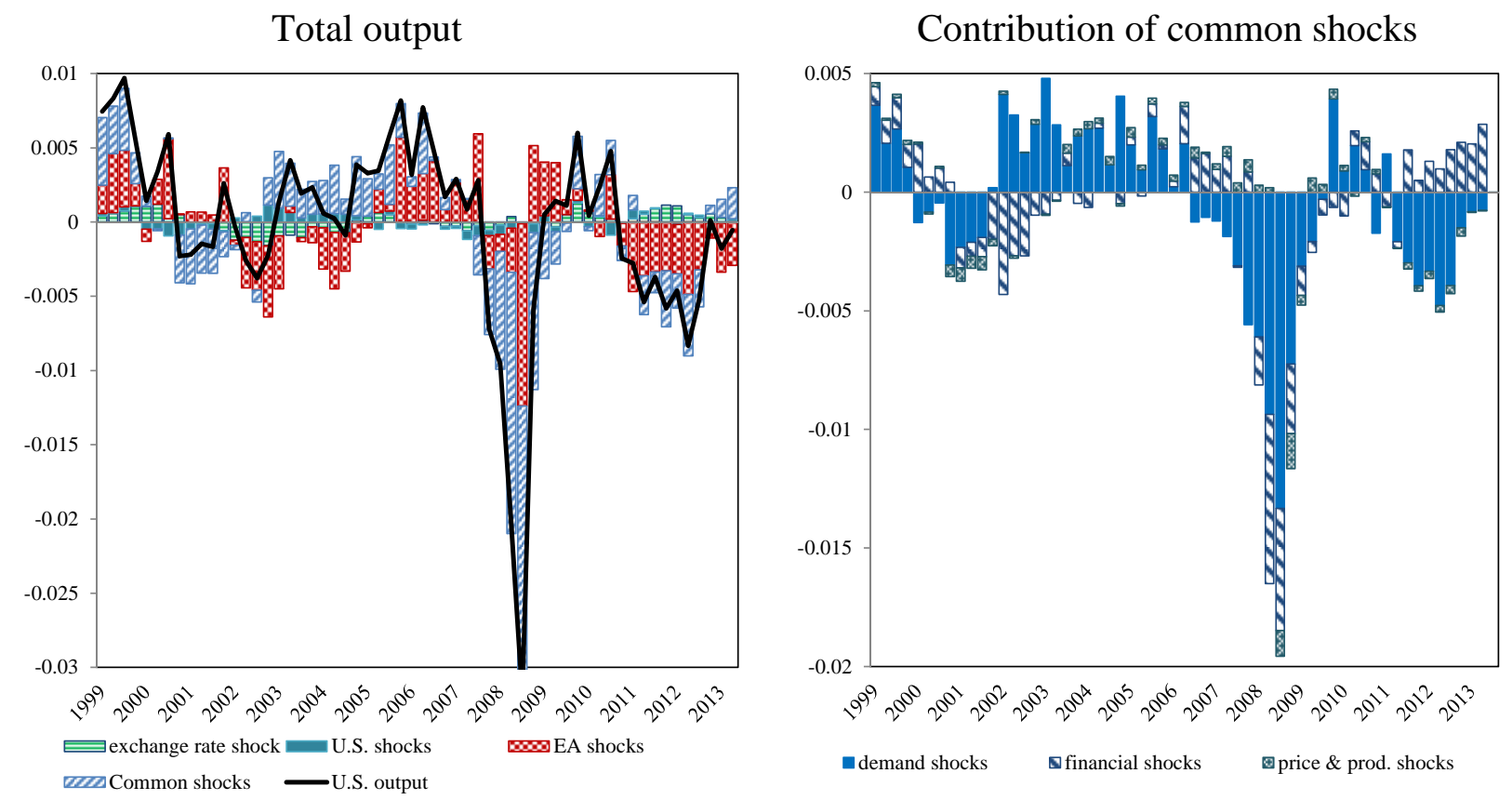

Contribution of common financial shocks

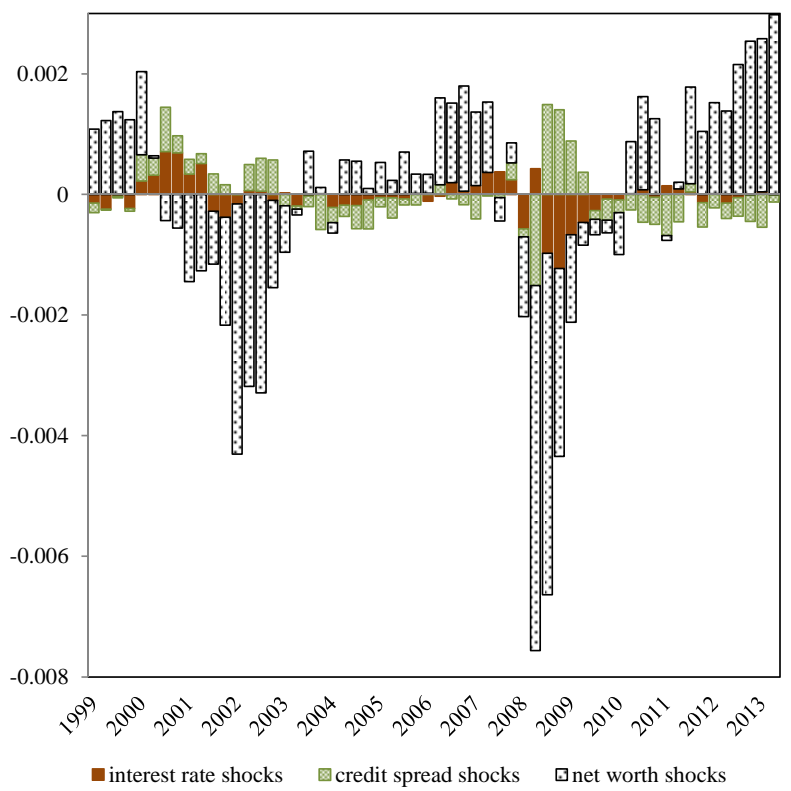

Contribution of common financial shocks

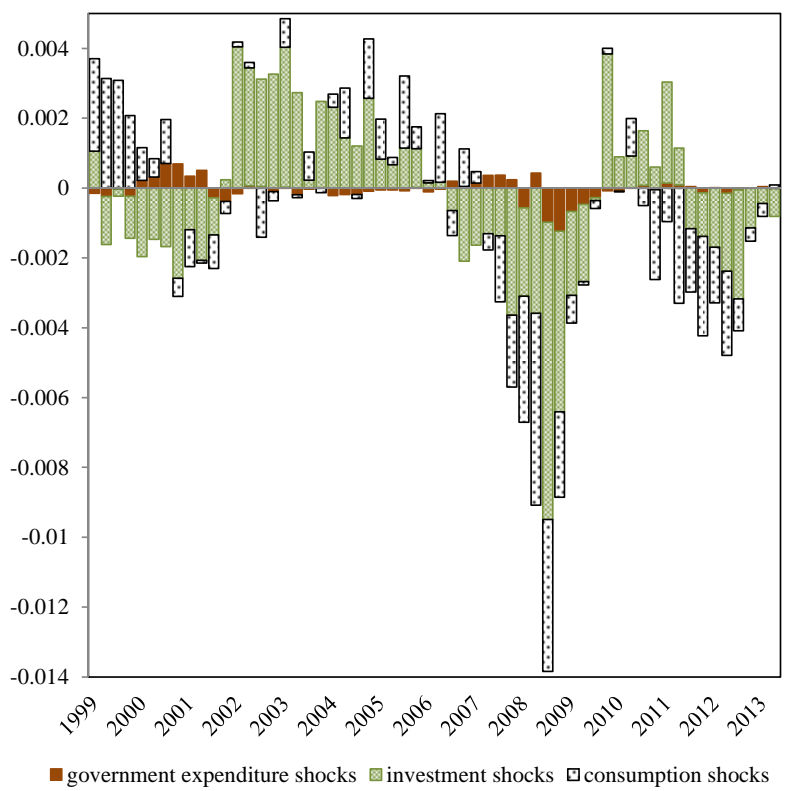

Notes: Demand shock includes, consumption, investment and government expenditure shocks. Financial shocks include credit spread, net worth and interest rate shocks. Price shocks include wage, domestic and foreign price shocks. 
Figure 7. A comparison of output responses across different models

\section{U.S. output responses to EA shocks and common shocks}

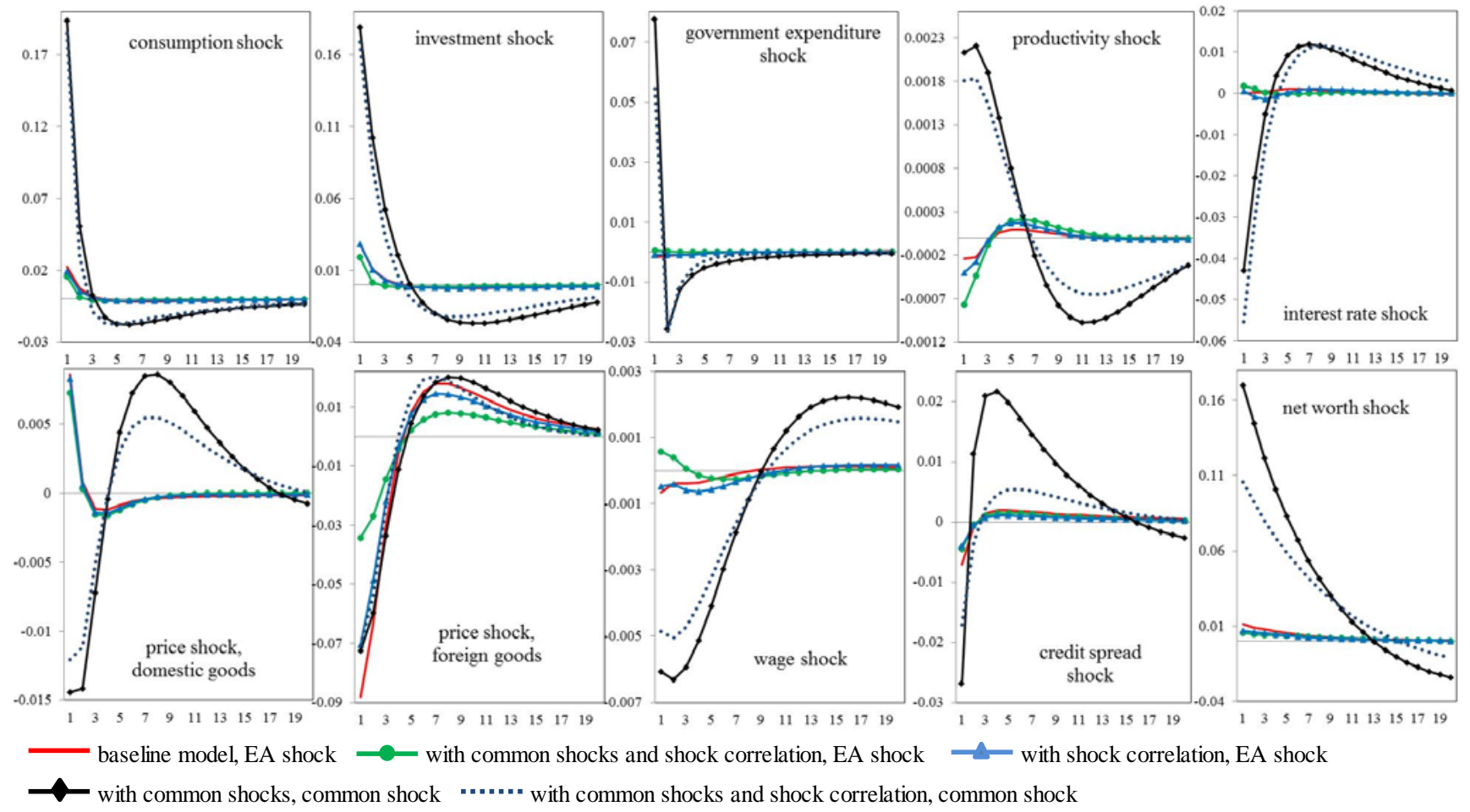

Euro Area output responses to US shocks and common shocks
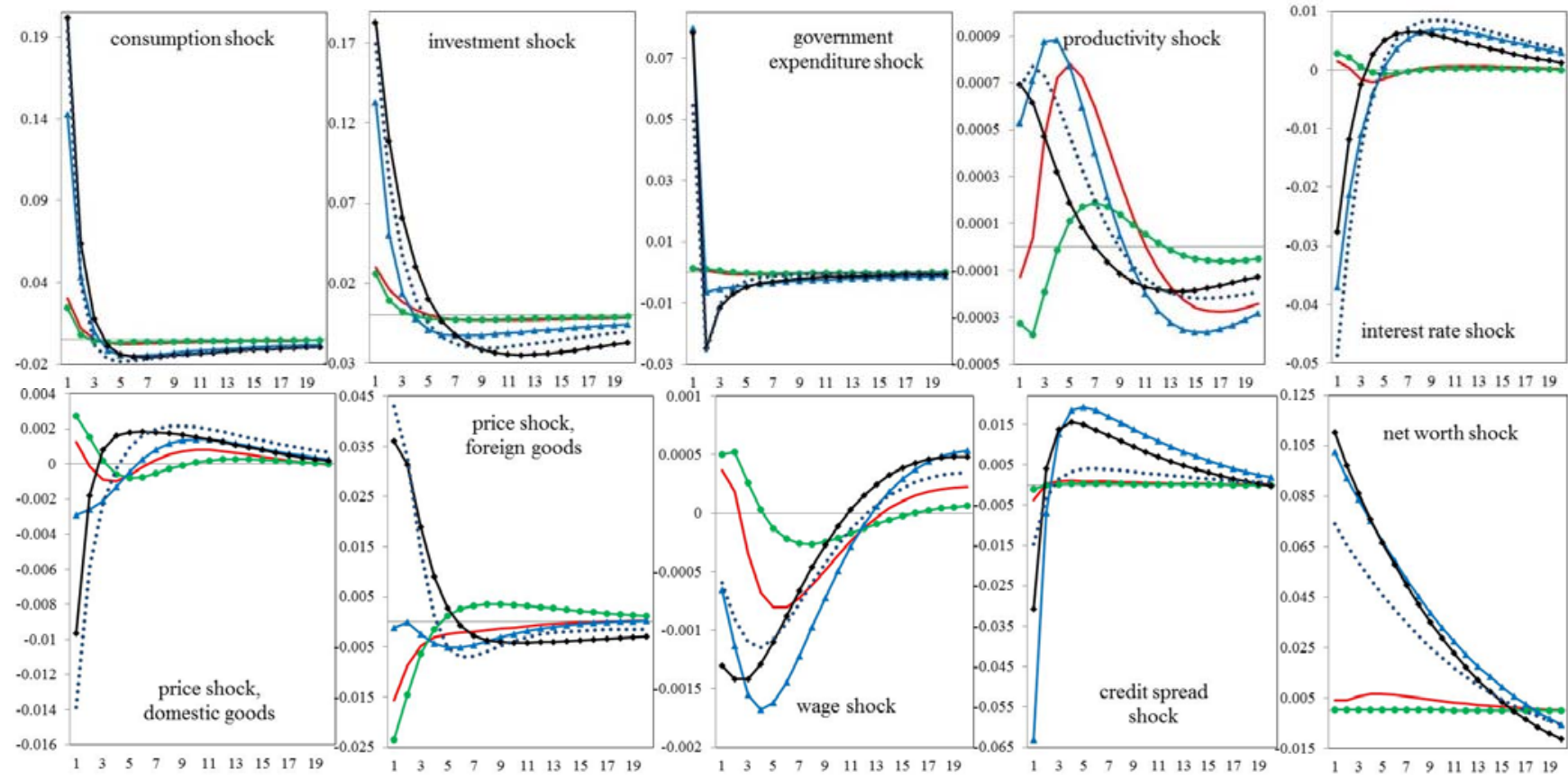

— baseline model, US shock

- with common shocks and shock correlation, US shock

- with shock correlation, US shock

with common shocks, common shock

....... with common shocks and shock correlation, common shock 